\title{
Characterisation of Damaged Tubular Composites by Acoustic Emission, Thermal Diffusivity Mapping and TSR-RGB Projection Technique
}

\author{
Neha Chandarana $^{1} \cdot$ Henri Lansiaux ${ }^{2} \cdot$ Matthieu Gresil $^{1}$ (D)
}

Received: 19 September 2016 / Accepted: 30 September 2016 / Published online: 15 November 2016

(C) The Author(s) 2016. This article is published with open access at Springerlink.com

\begin{abstract}
An increase in the use of composite materials, owing to improved design and fabrication processes, has led to cost reductions in many industries. Resistance to corrosion, high specific strength, and stiffness are just a few of their many attractive properties. However, damage tolerance remains a major concern in the implementation of composites and uncertainty regarding component lifetimes can lead to over-design and under-use of such materials. A combination of non-destructive evaluation (NDE) and structural health monitoring (SHM) have shown promise in improving confidence by enabling data collection in-situ and in real time. In this work, infrared thermography (IRT) is employed for NDE of tubular composite specimens before and after impact. Four samples are impacted with energies of $5 \mathrm{~J}, 7.5 \mathrm{~J}$, and $10 \mathrm{~J}$ by an un-instrumented falling weight set-up. Acoustic emissions (AE) are monitored using bonded piezoelectric sensors during one of the four impact tests. IRT data is used to generate diffusivity and thermal depth mappings of each sample using the thermographic signal reconstruction (TSR) red green blue (RGB) projection technique. Analysis of AE data alone for a $10 \mathrm{~J}$ impact suggest significant damage to the fibres and matrix; this is in good agreement with the generated thermal depth mappings for each sample, which indicate damage through multiple fibre layers. IRT and AE data are correlated and validated by optical micrographs taken along the cross section of damage.
\end{abstract}

Keywords Acoustic emission · Composites · Infrared thermography · Depth mapping · Nondestructive evaluation $\cdot$ Structural health monitoring $\cdot$ Piezoelectric sensors

Neha Chandarana

nehachandarana@outlook.com

Matthieu Gresil

matthieu.gresil@manchester.ac.uk

1 i-Composites Lab, School of Materials, University of Manchester, 79 Sackville Street, Manchester M1 3NJ, UK

2 Ecole Nationale des Arts et Industries Textiles (ENSAIT), Roubaix, France 


\section{Introduction}

Fibre reinforced polymer composite materials have become attractive for use in structural applications since they can provide advantages over traditional materials. Composites are more corrosion resistant than their metallic counterparts and provide high strength while delivering weight reductions. However, manufacturing costs, production rates and confidence regarding damage tolerance represent a significant challenge. The relative inexperience designing with composites means that industries are reliant on models and predictions regarding the response of these materials in service and how damage affects component lifetimes. This inexperience can often translate into conservative actions, leading to overdesigning and premature replacements of parts, which greatly affects the cost saving capability of a moving to composites.

Non-destructive evaluation (NDE) techniques are often adopted for periodic inspection of composite structures while they are in service. Inspection of structures in this way can reduce the life cycle cost of a component by preventing premature replacements, while also improving safety and reducing the likelihood of catastrophic failure. Common methods of NDE include the use of x-rays, ultrasonic waves [1], eddy currents [2], shearography [3-5], and infrared thermography [6-17]. Though non-destructive techniques (NDT) offer an insight into the performance of composite materials and the environments in which they operate, their implementation can represent significant down-time and labour costs. The use of structural health monitoring (SHM) systems has sparked interest in recent years as they can be integrated directly into a composite structure during manufacture [18, 19]. Sensors and embedded networks can be used to monitor various parameters such as local stress, strain, temperature, impact, delamination, and crack propagation in-situ and in real time [19-24]. Where the use of SHM and NDE are combined, it becomes possible to carry out "focused" inspections using non-destructive techniques, saving both time and money.

This paper presents an experimental study in the combination of real-time and in-situ health monitoring with non-destructive evaluation of tubular composite materials subjected to impact damage. Subsurface damage and delaminations, if not detected and monitored, can lead to catastrophic failure of the composite. In this work, the specimen is evaluated before and after impacting with a projectile, using active infrared thermography. During impact, bonded piezoelectric sensors record acoustic emission events. The combination of these methods and analyses of the data provide an insight into the specific damage types caused by impact.

\subsection{Infrared Thermography \& Thermal Diffusivity Mapping}

Infrared thermography (IRT) is a non-contact, non-invasive technique used to obtain a 2D image of the heat distribution across the surface of an object. IRT enables large areas of a material to be "scanned" relatively quickly (in the order of seconds), without causing any damage to components. The apparatus is more versatile than the alternatives and thus IRT can provide significant savings in time, labour and machinery compared to more traditional NDE techniques.

Active IRT is preferred for quick inspection of composite materials. Contrary to passive IRT, where the features of interest naturally present a thermal contrast, this approach requires an external source of energy to induce a relative thermal contrast. Examples of energy sources include optical flash lamps, heat lamps, hot/cold air guns, etc. Active IRT can be used in several modes: pulsed thermography, long pulsed heating/step heating transient thermography, 
optical lock-in thermography, and ultrasound lock-in thermography. In the analysis of large composite structures, such as aircraft, heat pulse thermography presents many advantages [13, 25]. The presence of a defect in a composite causes a discontinuity in the material. This causes the thermal resistance of the material in this region to increase, which induces a temperature difference between defective and non-defective regions, thus enabling the technique to be used for inspections during manufacture and in service.

Optical flash thermography has emerged as one of the most widely implemented techniques in the US since it is faster than the alternatives and facilitates quantitative measurement of thickness, depth and thermal diffusivity [26]. There are two modes by which heat pulse IRT can be used: transmission and reflection. The former of these tends to produce more accurate results, but requires access to both sides of the specimen which is often impractical, particularly for tubular structures. The application of active IRT for the analysis of tubular composites has been documented [27] however it is not possible to examine extended depths of a material (in the order of $\mathrm{mm}$ ), while environmental conditions may also affect the accuracy of the technique.

In reflective IRT, recording the cooling phase after thermal excitation by a flash heat pulse enables the detection of defects in composite materials. The value of thermal diffusivity in defective and non-defective regions of the sample varies, so analysis of each pixel in the thermal image allows a thermal diffusivity mapping to be plotted for the sample, whereby a coloured scale highlights defective or damaged regions. The thermal diffusivity, $\alpha$, is calculated from $t^{*}$ by plotting $\log \left(T(t, 0)-T_{0}\right)$ against $\log (t)$, where $T$ is the temperature at time $t[8$, 28]. This is shown in Fig. 1.

The thermal diffusivity of each pixel in the thermal image is calculated as:

$$
\propto=\frac{L^{2}}{\pi t^{*}}
$$

where $\alpha$ is the diffusivity $\left(\mathrm{m}^{2} / \mathrm{s}\right), L$ is the thickness of the sample $(\mathrm{m})$, and $t^{*}$ is the time at the intersection of the two tangents (s). Fitting of the data to reduce the noise content improves the detection of defects. The data fitting is done by a log-log polynomial equation $[8,28]$ :

$$
\log _{10}(T)=\log _{10}\left(\sum_{n} a_{n} t^{n}\right)
$$

where $T$ is the temperature, and $t$ is the time (s). This polynomial fitting is applied to each pixel of the thermal image, and the intersection of the two tangents allows the value of $t^{*}$, and consequently the thermal diffusivity, to be obtained. A colour mapping of the thermal diffusivity of each pixel in the image allows the defective regions to be highlighted against the sound parts of the material.

\subsection{TSR Polynomial Fitting and RGB Projection Technique}

The thermographic signal reconstruction in red, green and blue was first proposed by Roche and Balageas [29] as an approach for the inspection of composite materials and structures to evaluate the extent of real-life damage such as manufacturing and impact-induced defects. TSR, when applied to pulse thermography, allows the emphasis of thermal contrasts generated by defects inside the inspected material. It is possible to build a unique composite image by an RGB projection, whereby the colours of the image are linked directly to the variations in depth 
Fig. 1 Determination of $t^{*}$ (Inspired by [8])

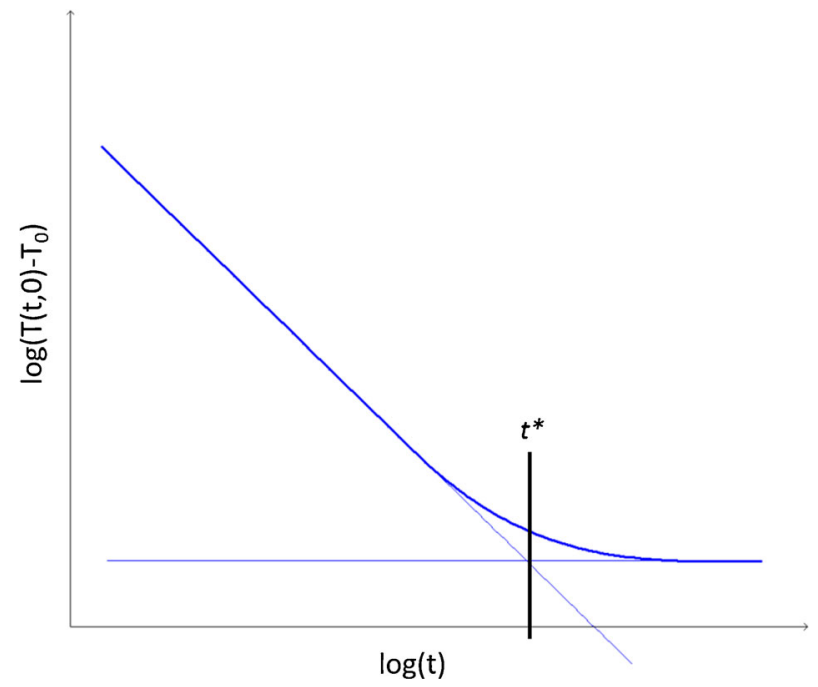

of different defects of the material. The proposed method uses the following TSR polynomial fitting of thermal data for obtaining the RGB coefficient images:

$$
\log _{10}(T)=\sum_{n} a_{n} \log _{10}(t)^{n}
$$

where $T$ is the temperature, $t$ is the time (s), and $n=7$. The result of this fitting provides $n+1$ coefficient images. The size of each coefficient image is the same as that of the raw data. The eight coefficient images produced by the fitting are studied to select the "best" three based on the detectability of defects. This trio of images is used to produce a TSR-coefficient RGBcomposite image. This process relies primarily on arbitrary eye-sensitivity criteria. The depth of defects can then be estimated by:

$$
z=L \sqrt{\frac{t_{d}}{t_{l}}}
$$

where $z$ is the depth of the defect, $L$ is the thickness of the sample, $t_{d}$ and $t_{l}$ are the emerging times of the defect rear face, respectively, as shown in Fig. 2. Once the depths have been estimated, it is possible to assign a scale to the RGB-composite image, resulting in a "thermal D scan". For more information about the process of obtaining the thermal depth mapping by the TSR-RGB projection technique, the reader is referred to [29, 30].

\subsection{Acoustic Emission Monitoring}

A rapid release of energy in a material caused by microstructural damage such as a matrix crack causes a transient elastic wave to be generated; this is known as an acoustic emission (AE). The high pitched ultrasonic waves propagate through the structure, being scattered and reflected by discontinuities in the materials. Piezoelectric wafer active sensors (PWAS) can be embedded in or bonded to the surface of composite materials as receivers of these waves. A network of three or more sensors can be used to determine the location of the damage source and estimate the severity and type of damage. 
Fig. 2 Theoretical time-evolution of temperature for damaged and undamaged areas of the specimen (Inspired by [29])

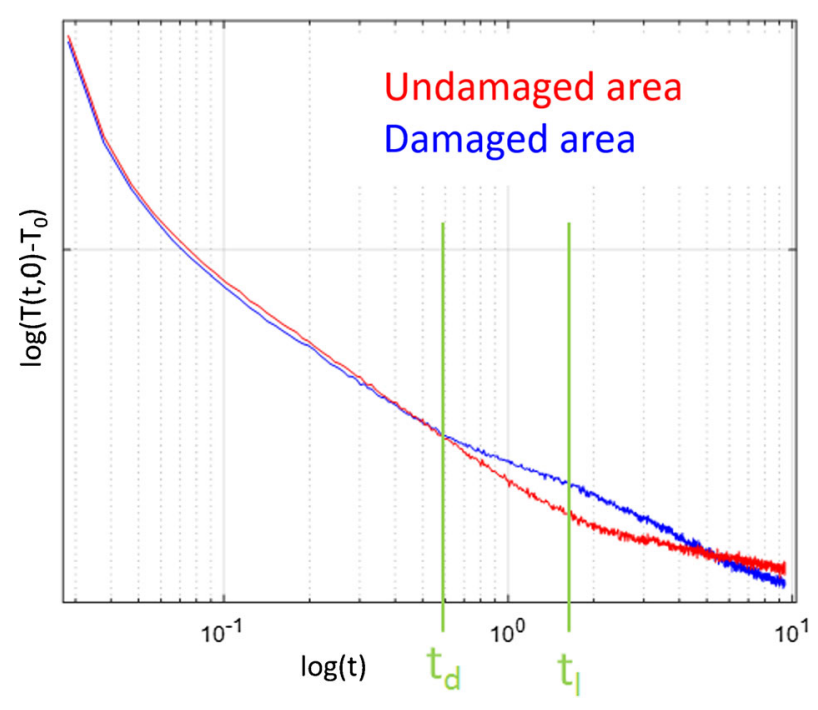

The use of AE monitoring for detection of early damage in composite materials is well established [35]. Forty years of research have led to the agreement that there are four main damage mechanisms identifiable in composite materials by their acoustic emission "signature" [36, 37]: (i) matrix cracking, (ii) interfacial debonding, (iii) fibrematrix friction/fibre pull-out, and (iv) fibre breakage. Researchers have used many different methods to distinguish these damage mechanisms during mechanical testing including, but not limited to, classification of acoustic signature [20, 37-39], amplitude and frequency distribution analysis [20,37-57], and analysis of different features of the waveform [37, 44]. Figure 3 shows a typical AE signal and the parameters that are commonly used for analysis of AE-generating damage events. Typical waveforms have also been associated with different damage modes based on the signal geometry: A-type signals (slow increase times around 10-20 $\mu \mathrm{s}$ ) are associated with matrix cracking, Btype (sharp rising, lasting for around $10 \mu \mathrm{s}$ and abruptly decreasing) associated with

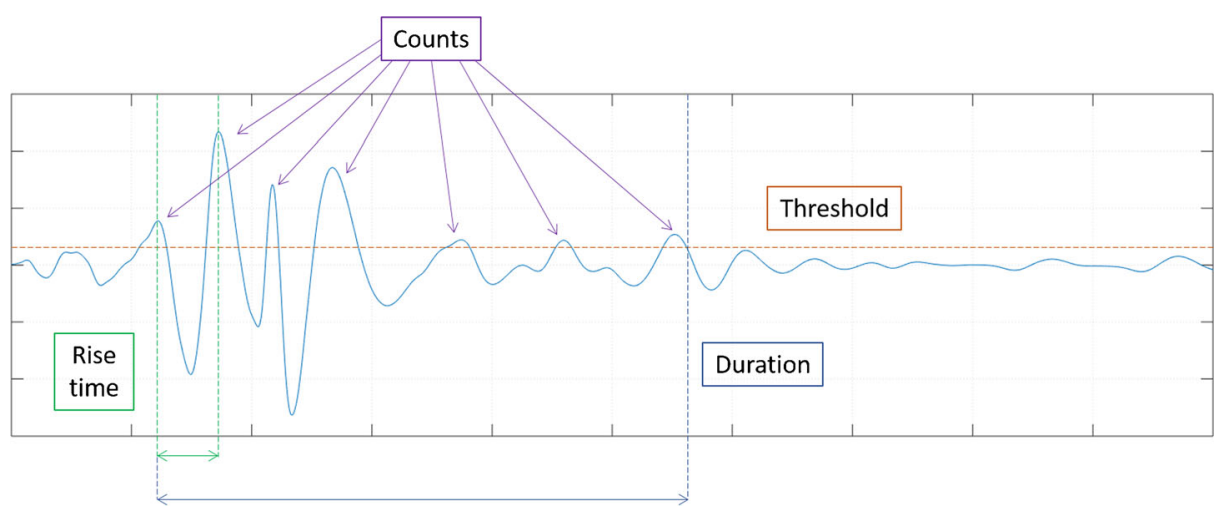

Fig. 3 Typical AE signal features 
fibre/matrix debonding, C-type signals associated with fibre breakage, and D-type (long rising times, high amplitudes, and long duration) are associated with delamination [37].

Tables 1 and 2 show a compilation of the amplitude and frequency distributions used to classify different damage mechanisms that have been encountered in the literature. These studies clearly demonstrate the difficulty of identifying damage modes in composite materials, though there is a clear trend that shows an increase in both amplitude and frequency, as the type of damage becomes more severe. The waveforms obtained can be dependent on many parameters including, but not limited to: the choice of sensors, method of coupling/bonding between the sensors and host structure, structural materials used, number of sensors, size of the specimen, arrangement and spacing of sensors, etc.

Much of the research reported is based on 2D and 3D composite laminates rather than cylindrical structures. A small number of investigations are reported for AE monitoring of glass fibre tubular composites [58-60] and composite pressure vessels [61], however the specific AE waveform data has not always been made available.

The use of a monitoring technique like AE can enable more focused inspections of structures in industries such as aerospace, where inspection time results in physical down-time. More detailed information about the service environment and in-situ structural data can prompt in-depth investigations to analyse the areas of stress concentrations. This type of data can feed back into optimising the design process as well as for accurate modelling of components. AE and IRT have been found to be complementary when combined $[10,16]$ although reported instances of this are limited. Spatial detection of defects by AE monitoring represents a significant advantage, while IRT can be used to verify and analyse the size and severity of damage. Targeted inspections can be carried out as and when required, and save time since the whole structure need not be evaluated.

\subsection{Guided Wave Propagation in Tubular Composites}

Ultrasonic guided wave based SHM is one of the most prominent options for inspection and monitoring of composite materials. It is necessary to understand the characteristics and modes of wave propagation through the material and the interaction of these waves with defects and damage in the structure.

In solid hollow cylinders, three primary wave modes can propagate: (i) longitudinal modes which propagate along the axial direction by compressional motion, (ii) torsional modes which propagate along the axial direction by shear motion parallel to the circumferential direction, and (iii) flexural modes which propagates along the axis by flexural motion in the radial direction. The longitudinal and torsional modes in a cylinder are axisymmetric and can be considered as equivalent to Lamb waves and $\mathrm{SH}$ waves in plate structures, respectively [31-33]. The flexural mode is non-axisymmetric and is considered the true specific mode for cylindrical structures [34].

Guided waves can propagate over long distances without significant loss of energy, which makes them well suited for the inspection of large structures such as bridges, aircraft, ships, missiles, pressure vessels, pipelines, etc. It is important to study the propagation of waves for the purpose of acoustic emission in tubular composites to be able to understand the difficulties when analysing waves for quantification of structural damage and defects. 


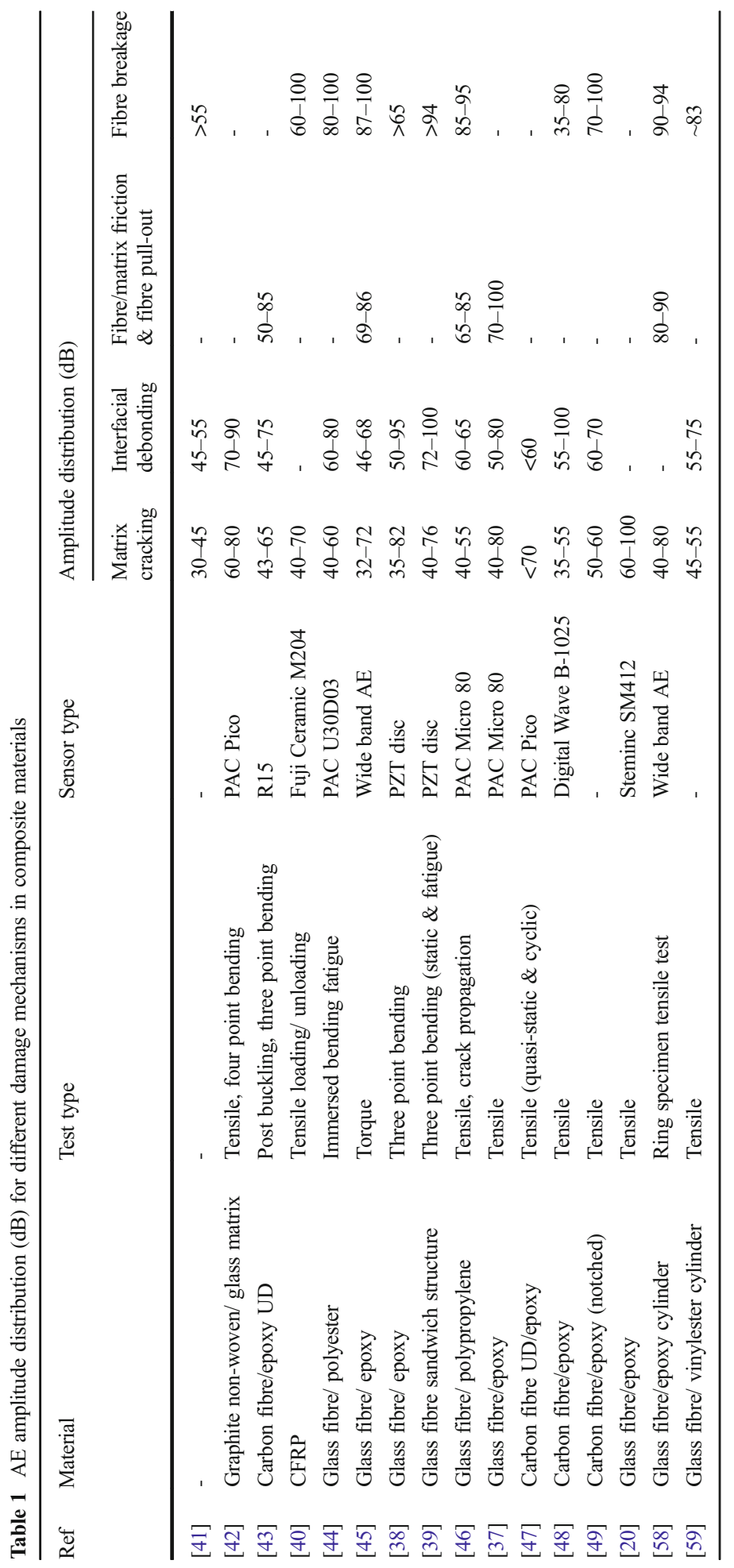




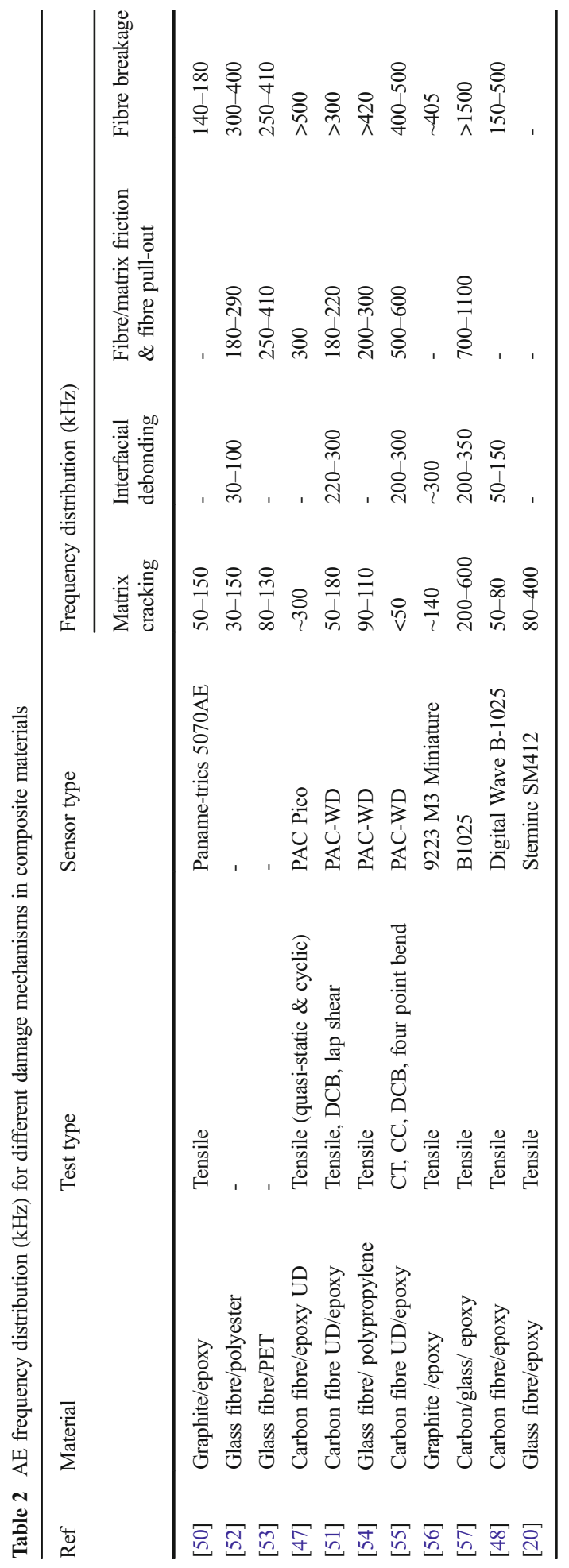


Table 3 Geometry and mechanical properties of composite cylinder from the manufacturer

\begin{tabular}{llllll}
\hline $\begin{array}{l}\text { Internal } \\
\text { diameter } \\
(\mathrm{ID}, \mathrm{mm})\end{array}$ & $\begin{array}{l}\text { Wall } \\
\text { thickness }(\mathrm{mm})\end{array}$ & $\begin{array}{l}\text { Density, } \rho \\
\left(\mathrm{kg} / \mathrm{m}^{3}\right)\end{array}$ & $\begin{array}{l}\text { Young's } \\
\text { modulus, E }(\mathrm{GPa})\end{array}$ & $\begin{array}{l}\text { Shear modulus, } \\
\mathrm{G}(\mathrm{GPa})\end{array}$ & $\begin{array}{l}\text { Poisson's } \\
\text { ratio, } v\end{array}$ \\
\hline 47.5 & 1.4 & 1600 & $\begin{array}{c}\mathrm{E}_{1}=90, \mathrm{E}_{2}=19, \\
\mathrm{E}_{3}=19\end{array}$ & $\begin{array}{c}\mathrm{G}_{12}=4.6, \mathrm{G}_{23}=4.6, \\
\mathrm{G}_{13}=4.6\end{array}$ & $\begin{array}{c}v_{12}=0.14, v_{23}=0.2, \\
v_{13}=0.2\end{array}$ \\
\hline
\end{tabular}

\section{Experimental Methods}

\subsection{Materials}

Two hollow composite cylinders manufactured from a hybrid of unidirectional pre-preg carbon fibres (Toray T700) oriented in the axial direction $\left(0^{\circ}\right)$ and unidirectional pre-preg E-glass fibres oriented in the circumferential direction $\left(90^{\circ}\right)$ were used (supplied by Easy Composites Ltd). The lay-up order of fibres is $[0,90,0,90,0]$. The geometry and mechanical properties of the tubes are shown in Table 3 and calculated dispersion curves for the 1st, 2nd and 3rd longitudinal modes are shown in Fig. 4.

The tubes were cut into sections for each impact experiment as shown in Table 4. Sample 4 is instrumented with eight PWAS (StemInc SM412, $7 \mathrm{~mm}$ diameter, $0.2 \mathrm{~mm}$ thickness) for AE monitoring during impact of the specimen. The surface of the tube was prepared for optimisation of IR imaging by abrasion of the surface with a scourer pad. The surface of Sample 4 was also coated with a matt black acrylic paint to further optimise the surface for imaging.

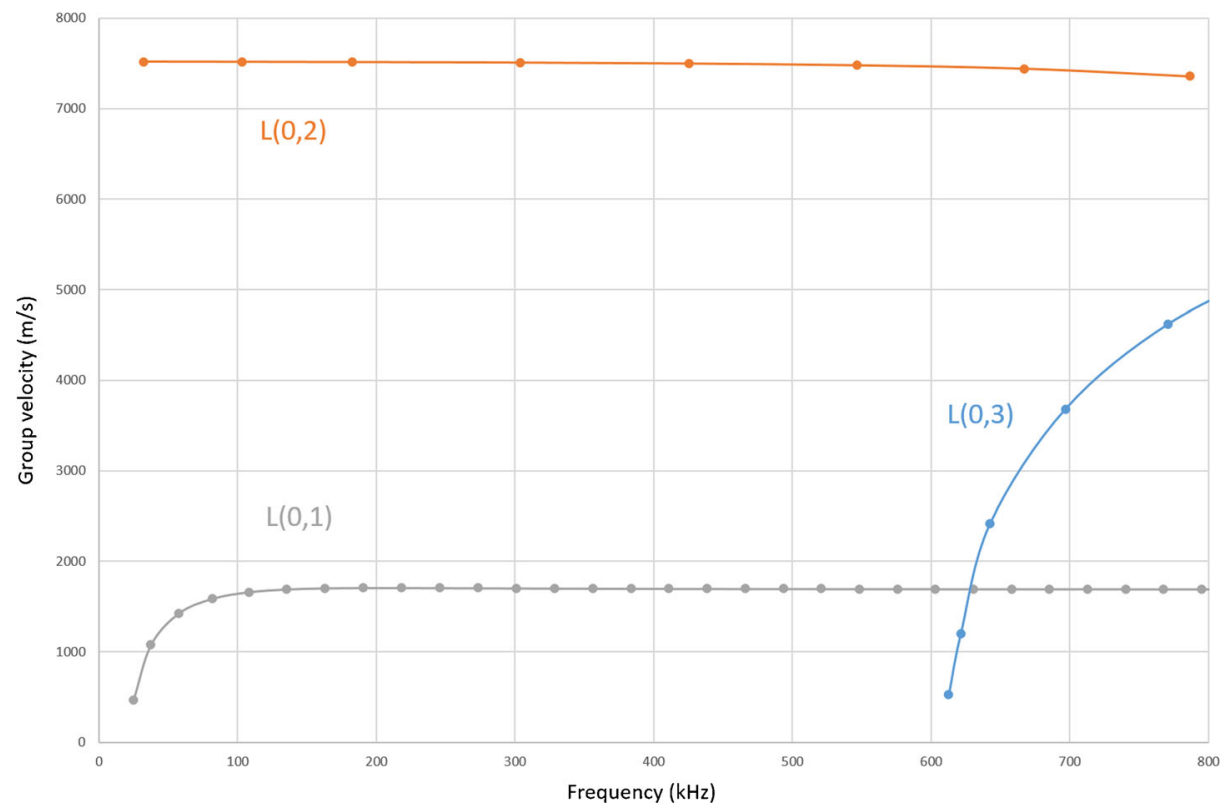

Fig. 4 Calculated dispersion curves for the hollow composite tube used 
Table 4 Low velocity impact samples

\begin{tabular}{llll}
\hline Sample & Section length & Theoretical impact energy & Data acquisition \\
\hline 1 & $300 \mathrm{~mm}$ & $10 \mathrm{~J}$ & IRT \\
2 & $300 \mathrm{~mm}$ & $7.5 \mathrm{~J}$ & IRT \\
3 & $300 \mathrm{~mm}$ & $5 \mathrm{~J}$ & IRT \\
4 & $400 \mathrm{~mm}$ & $10 \mathrm{~J}$ & AE \& IRT \\
\hline
\end{tabular}

\subsection{Impact Set-up}

The experimental set-up for impacting the tube is shown in Fig. 5. The support design is inspired by ASTM Standard G14-04 [62]. The tube is held to the support by elasticated straps to prevent vibration when impacted. The tube was impacted with an un-instrumented hemispherical striker with a mass of $510.61 \mathrm{~g}$. The starting height of the projectile was adjusted to achieve a variation in impact energy.

During the impact of Sample 4, the adhesively bonded PWAS receive AE signals which are recorded by the software 'AEWin' from Mistras with a sampling rate of $10 \mathrm{MHz}$ and $20 \mathrm{~dB}$ of pre-amplification per sensor. Four PWAS were damaged prior to impact, so just four sensors were used to record AE data. The digital filter is set to

Fig. 5 Set-up of the composite tube for impact

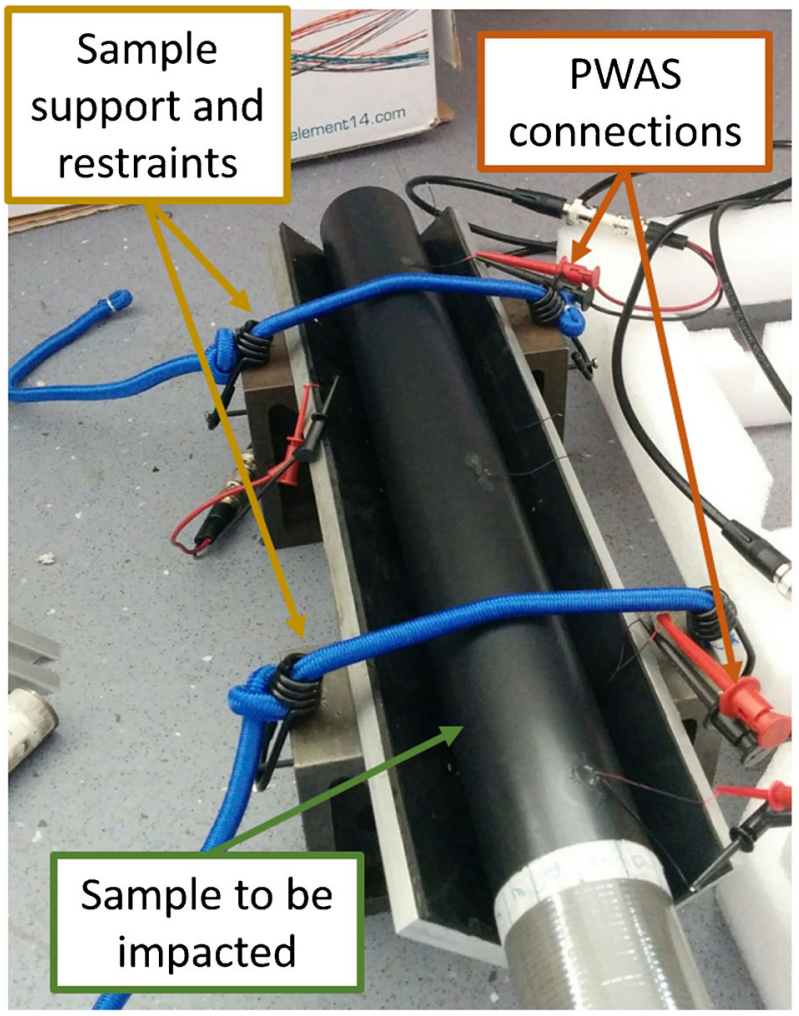


Fig. 6 Infrared thermography setup

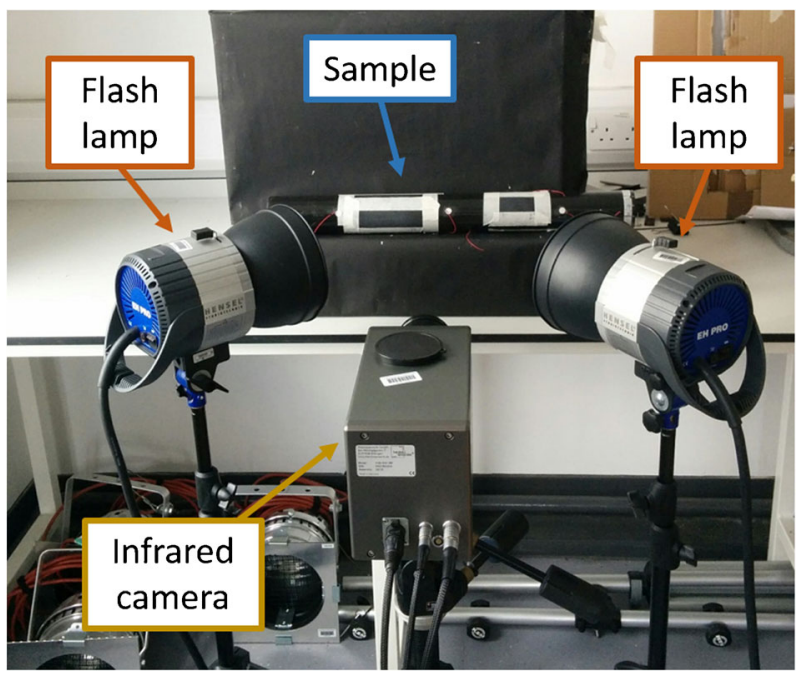

$100 \mathrm{kHz}-1 \mathrm{MHz}$ and the acquisition threshold is set to $55 \mathrm{~dB}$ to eliminate extraneous noise in the acoustic range during the experiment.

\subsection{IR Thermography Set-up}

The composite tube is scanned using an infrared camera (Thermosensorik InSb 640SM) before and after each impact. Two thermal flash lamps (HENSEL Studiotechnik powered by HENSEL Tria 6000S) deliver a combined pulse of approximately $6 \mathrm{~kJ}$ over a duration of $10.6 \mathrm{~ms}$ during each flash, during which the IR camera records an array of $640 \times 200$ pixels for each image of the sample. Figure 6 shows the set-up for imaging of each sample before and after impact.

Since the sample is tubular, in order to obtain thermal images from which a diffusivity mapping can be plotted, it is necessary to rotate the tube and take an image of each face. In this paper, the circumference of the tube was divided into twelve faces. Twelve images were taken of each sample and stitched together so that the final mapping is done on an "open cylinder". This process is illustrated in Fig. 7. The raw data captured by the infrared camera was used for analysis by all three thermal techniques utilised in this work: diffusivity mapping, TSR-RGB projection, and defect depth mapping.

Thermal analysis of the samples relies on a number of assumptions about the sample: (i) the front face of the specimen is uniformly heated by the flash pulse, (ii) the specimen thickness is uniform, and (iii) the specimen is opaque to the pulse of light and thermal radiation.

\section{Results and Discussion}

\subsection{Tested Specimens}

The photographs of samples 2 and 4 after impact are shown in Fig. 8. It is clear for both samples that the impact has caused some damage on the surface, resulting in the splitting of 
Fig. 7 2-D mapping of tube circumference
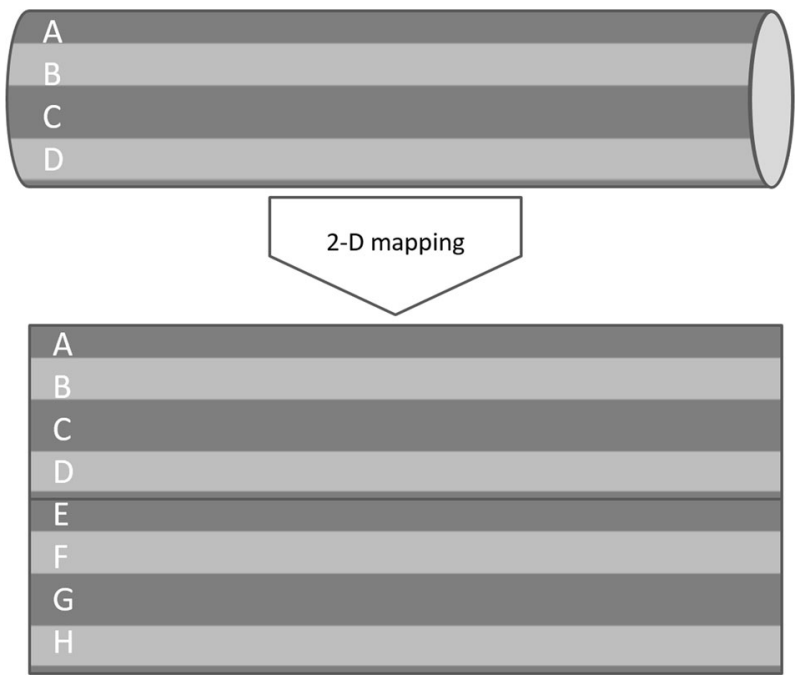

axially oriented carbon fibres (matrix cracking). There is some evidence of the formation of circumferential cracks on impact as well, however without further investigation, it is almost impossible to gauge the full extent of the damage caused to either sample. The surface cracks observed on Samples 1 and 3 were also of a similar nature. The length of the axial crack on Sample 4 suggests that the actual impact may not have been as high as $10 \mathrm{~J}$, since the impacts on Samples 1 and 2 (10 J and $7.5 \mathrm{~J}$ impacts, respectively) result in longer axial cracks, and the impact on Sample 3 (5 J impact) is visually similar to Sample 4. It is possible that the projectile did not impact the top of the cylinder's circumference, thus causing the damage to propagate differently. It is also important to keep in mind that out-of-plane damage to composite materials can often cause severe damage to the structure internally, though it may not be visible by eye.

Fig. 8 Photographs of the impact damage on (a) Sample 2-7.5 J impact, and (b) Sample 4-10 J impact
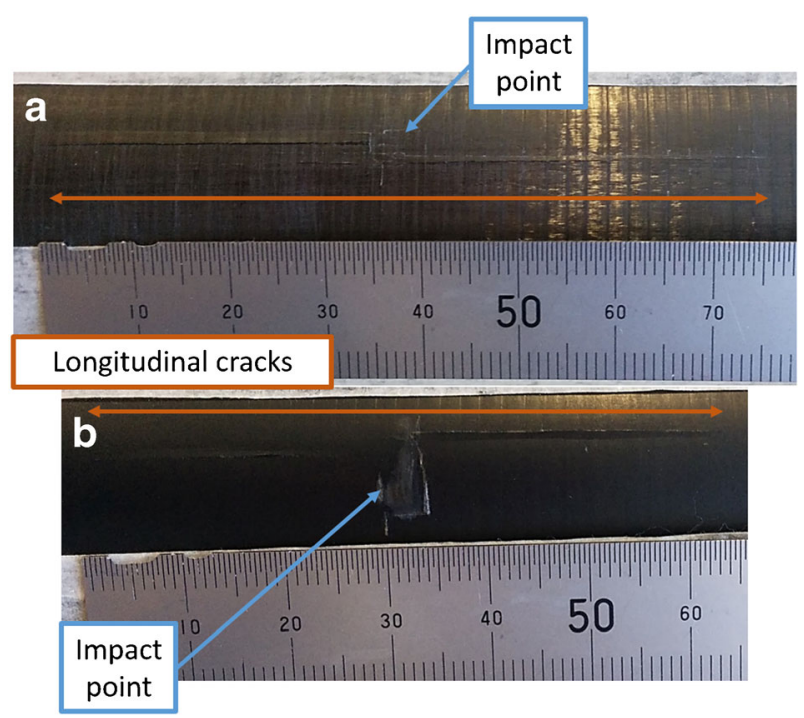

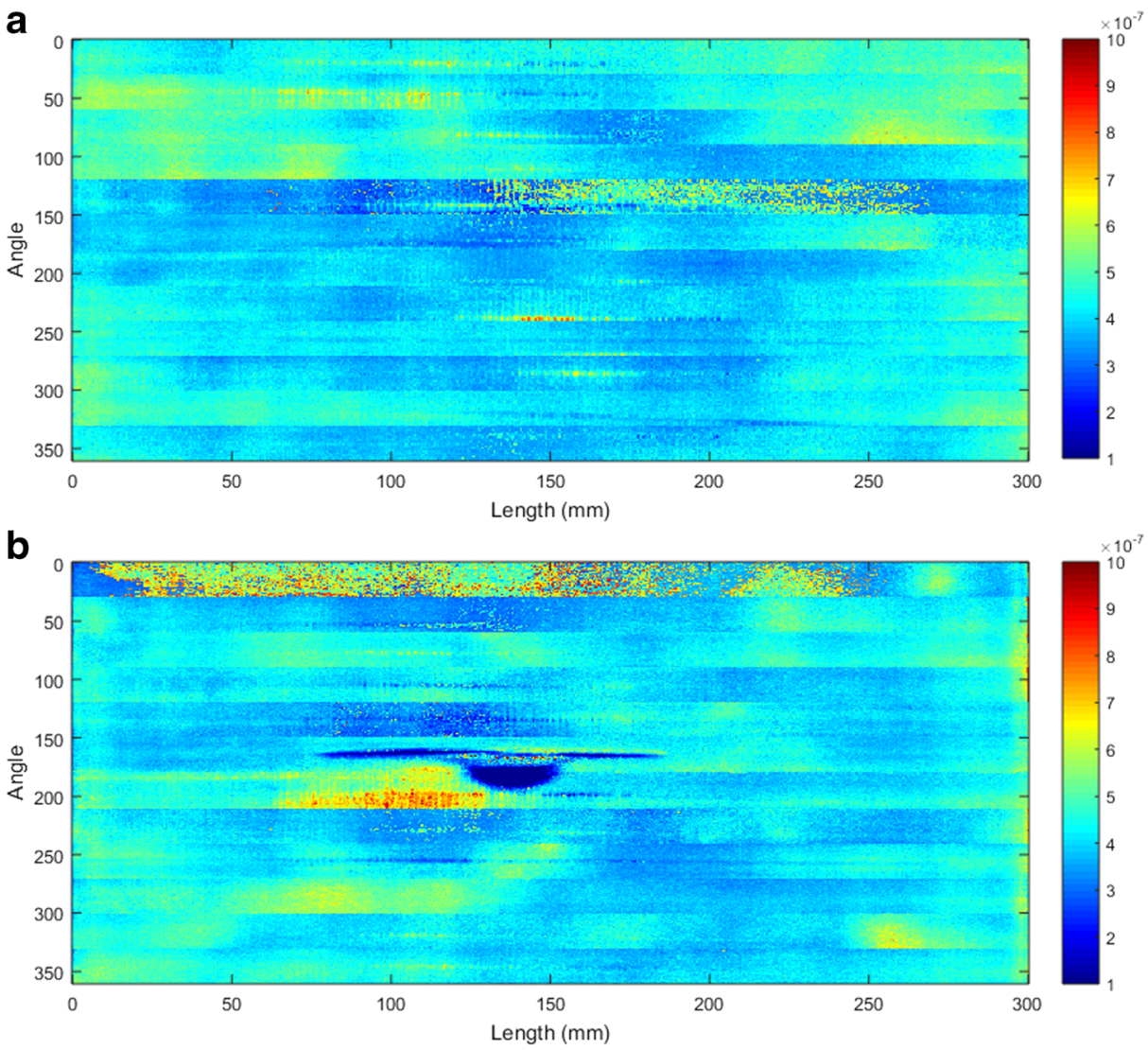

Fig. 9 Thermal diffusivity mapping of Sample 1 (a) before, and (b) after $10 \mathrm{~J}$ impact. The scale bar shows the thermal diffusivity, $\alpha(\mathrm{m} 2 / \mathrm{s})$

\subsection{Infrared Thermography and Thermal Diffusivity Mapping}

The diffusivity mapping was obtained for each sample by calculation of the diffusivity of each individual pixel in the raw image. This is done by calculation of $t^{*}$ which requires the fitting of two tangents. A minimum correlation coefficient of 0.99 is used to fit the tangent to the curve. Figure 9 shows the thermal diffusivity mapping of Sample 1 before and after impact.

The mean diffusivity $(\alpha)$ before impact is $3.90 \times 10^{-7} \mathrm{~m}^{2} / \mathrm{s}$. The coloured scale indicates the value of thermal diffusivity for each pixel in the image. The noise visible in the mapping is attributed to the reflection of light from the surface of the tube; since all of the incident energy is not absorbed by the material, the remainder is reflected back towards the IR camera and results in a higher value of thermal diffusivity. The impact is located $140 \mathrm{~mm}$ along the length and $160^{\circ}$ around the circumference of the tube. This analysis is relative, since the thermal diffusivity of the sample is affected by many parameters including the surface preparation, thickness, coatings, etc.

Moving the IR camera closer to the sample during imaging allows a higher resolution diffusivity mapping of the defect to be obtained, as shown in Fig. 10. Measurement of the width of each sample here allows for comparison between each of the defects. Table 5 shows 

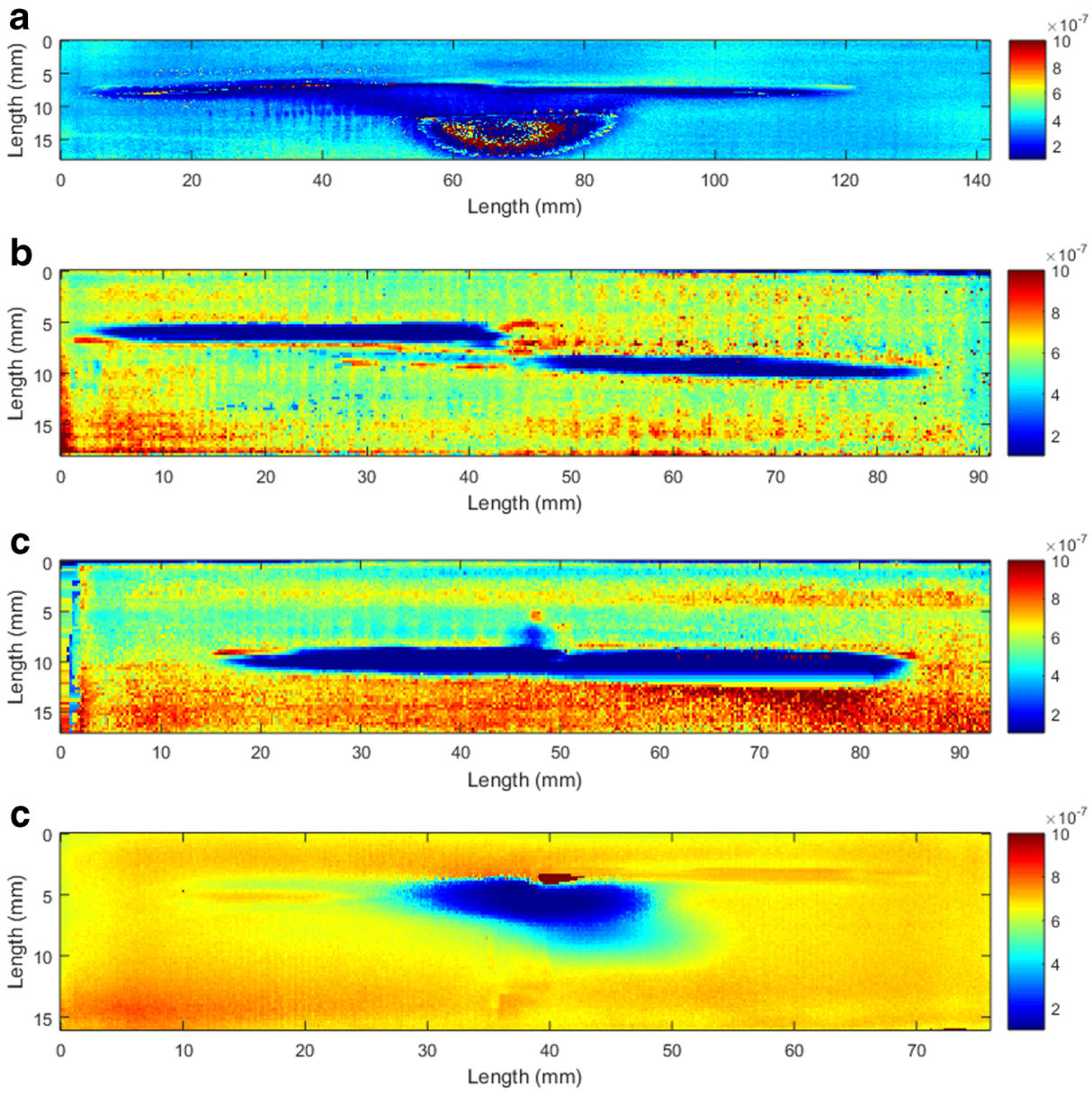

Fig. 10 Thermal diffusivity mapping focused on the impact location on (a) Sample 1-10 J impact, (b) Sample 2-7.5 J impact, (c) Sample 3-5 J impact, and (d) Sample 4-10 J impact. The scale bar shows the thermal diffusivity, $\alpha(\mathrm{m} 2 / \mathrm{s})$

the approximate width of the damage caused to each of the samples following impact. It should be noted here that although the thermal contrast is high for the damage on Sample 4, closer inspection reveals a lower thermal contrast between 10 and $70 \mathrm{~mm}$ (Fig. 8d), suggesting the damage may span $60 \mathrm{~mm}$ across the tube.

The geometry of the damage area as the impact energy is increased shows a trend, despite the difference in the relative size of damage on each Sample. Due to the layup of fibre plies in

Table 5 Width of damage visible in thermal diffusivity mapping

\begin{tabular}{lll}
\hline Sample & Impact energy $(\mathrm{J})$ & Width of damage $(\mathrm{mm})$ \\
\hline 1 & 10 & 110 \\
2 & 7.5 & 80 \\
3 & 5 & 70 \\
4 & 10 & $23(60)$ \\
\hline
\end{tabular}



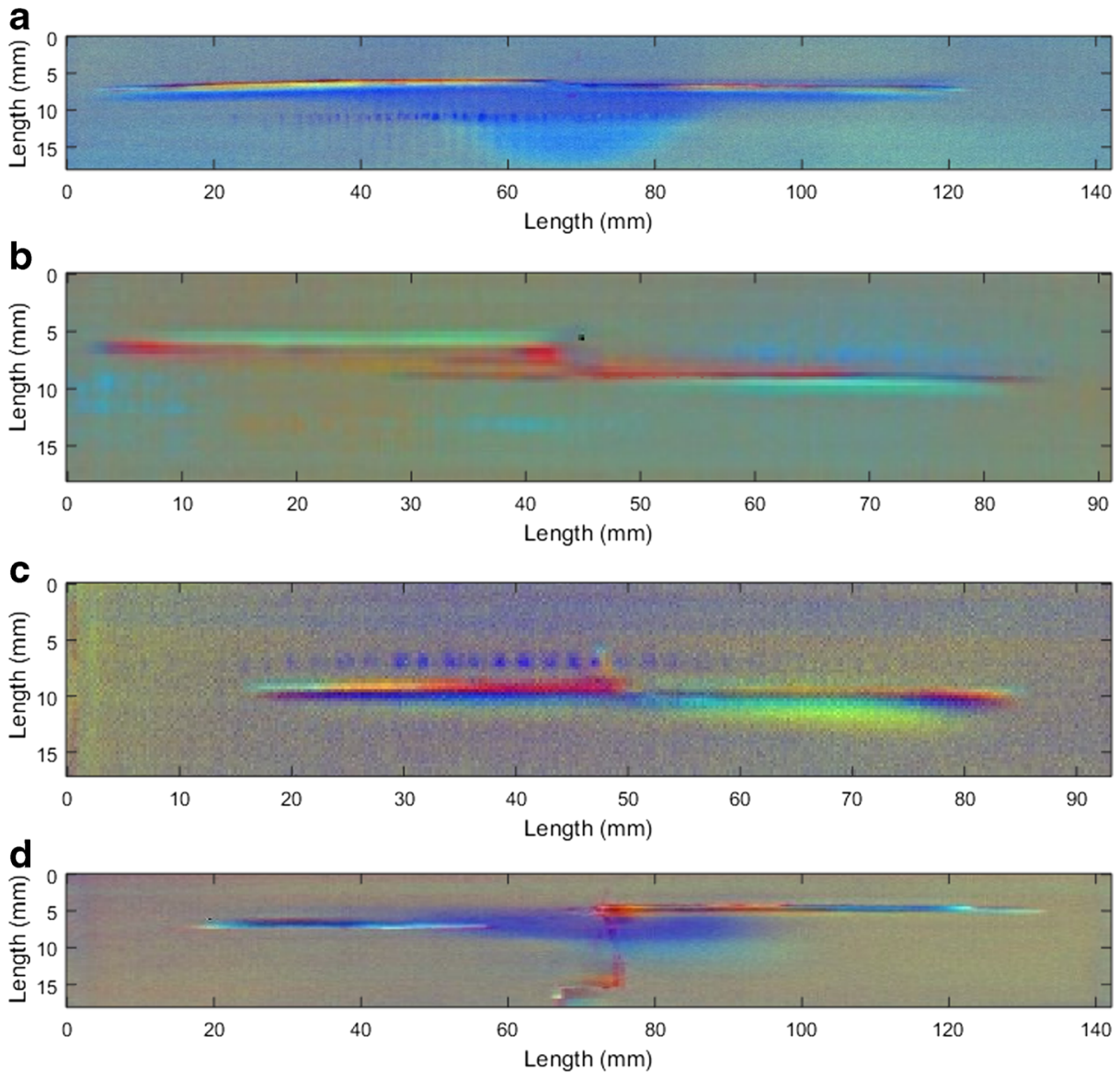

Fig. 11 RGB-composite images for impacts on (a) Sample 1-10 J impact, (b) Sample 2-7.5 J impact, (c) Sample 3-5 J impact, and (d) Sample 4-10 J impact

this tube $-[0,90,0,90,0]$ - even the lowest impact energy causes axial damage, which occurs as cracks form in the matrix between axial $\left(0^{\circ}\right)$ carbon fibres. It does not take a large force to separate these fibres. However, as the impact load is increased, the damage area spreads further around the circumference of the material, indicating the fracture of circumferential $\left(90^{\circ}\right)$ glass fibres and further matrix cracking, possibly leading to delamination. The diffusivity mapping of Sample 4 confirms the previous hypothesis that the projectile may have struck the tube slightly to one side of the top of the circumference. This could explain the difference in contrast between the longitudinal and transverse damage visible.

\subsection{RGB Projection}

The RGB-composite images obtained for the fours samples are shown in Fig. 11. Each image is obtained by the projection of three coefficient images - red, green, and blue - as shown in Table 6. A minimum correlation coefficient of 0.99 was used for the fitting of the data required to obtain the coefficient images (Eq. 3) [29]. 
Table 6 RGB coefficient images chosen for each sample

\begin{tabular}{llll}
\hline Sample & Red & Green & Blue \\
\hline 1 & 6 & 7 & 4 \\
2 & 5 & 3 & 7 \\
3 & 5 & 4 & 7 \\
4 & 6 & 7 & 4 \\
\hline
\end{tabular}

The RGB-composite images for samples 1 and 4 suggest the presence of transverse cracking close to the impact location. It appears at this stage that the colour contrast in the image for Sample 2 is not as high as for the other three samples. Since the thermal depth mapping is calculated from the RGB-composite images, it is possible that this could be affected (Fig. 12).
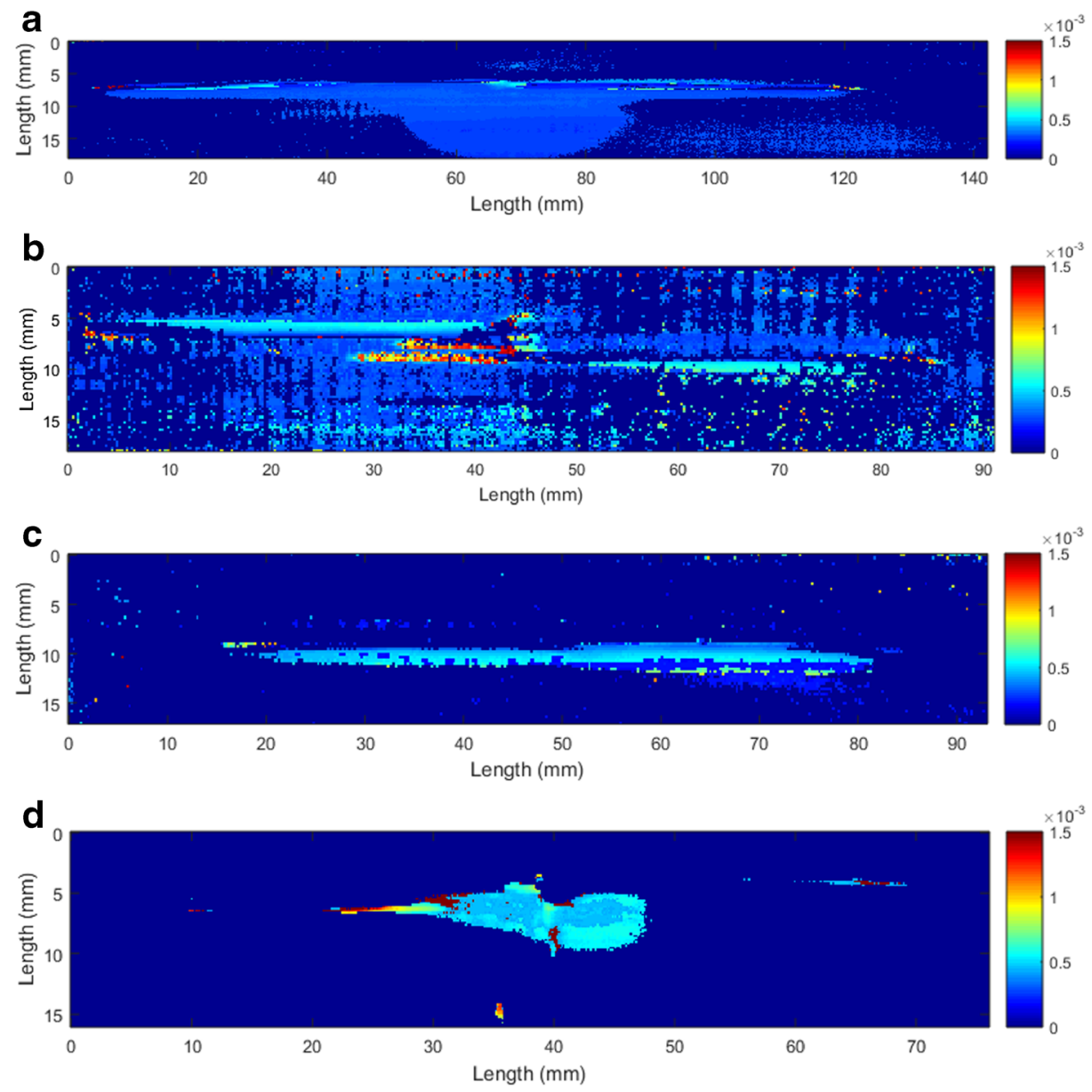

Fig. 12 Thermal D-scan of impact location on (a) Sample 1-10 J impact, (b) Sample 2-7.5 J impact, (c) Sample 3-5 J impact, and (d) Sample 4-10 J impact. The scale bar shows the defect depth, $\mathrm{m}$ 


\subsection{Thermal Depth Mapping}

The depth of the damage in each of the samples is calculated from each RGBcomposite image using Eq. 4. The coordinates of a reference point in the nondefective region must be provided by the user to generate the thermal depth mapping. The value of $t_{l}$ was manually defined as $3.162 \mathrm{~s}$.

Analysis of the depth mapping data reveals that the $10 \mathrm{~J}$ impact on Sample 4 has resulted in deeper damage when compared with Sample 1, although the diffusivity mapping had previously suggested a significantly smaller damage area. This demonstrates clearly the advantage of mapping both the diffusivity and the using RGB-coefficient images to map the depth of defects. The noise observed in the depth mapping of Sample 2 is attributed to a combination of factors, namely the reflection of light from the surface of the tube (which also affected the clarity of the thermal diffusivity mapping) and the lower contrast observed in the chosen RGBcomposite image for this specimen relative to the other three images. As mentioned previously, it may be possible to apply surface treatments/coatings to improve the clarity of the mapping obtained, by reducing the amount light reflected from the surface.

\subsection{Acoustic Emission Monitoring}

Figure 13 shows a typical AE waveform received immediately after impact; this waveform is from Sensor 1 . There are two primary guided wave modes observed, with a dominant $L(0,2)$ mode. Figure 14 shows the continuous wavelet transform (CWT) magnitude as a function of
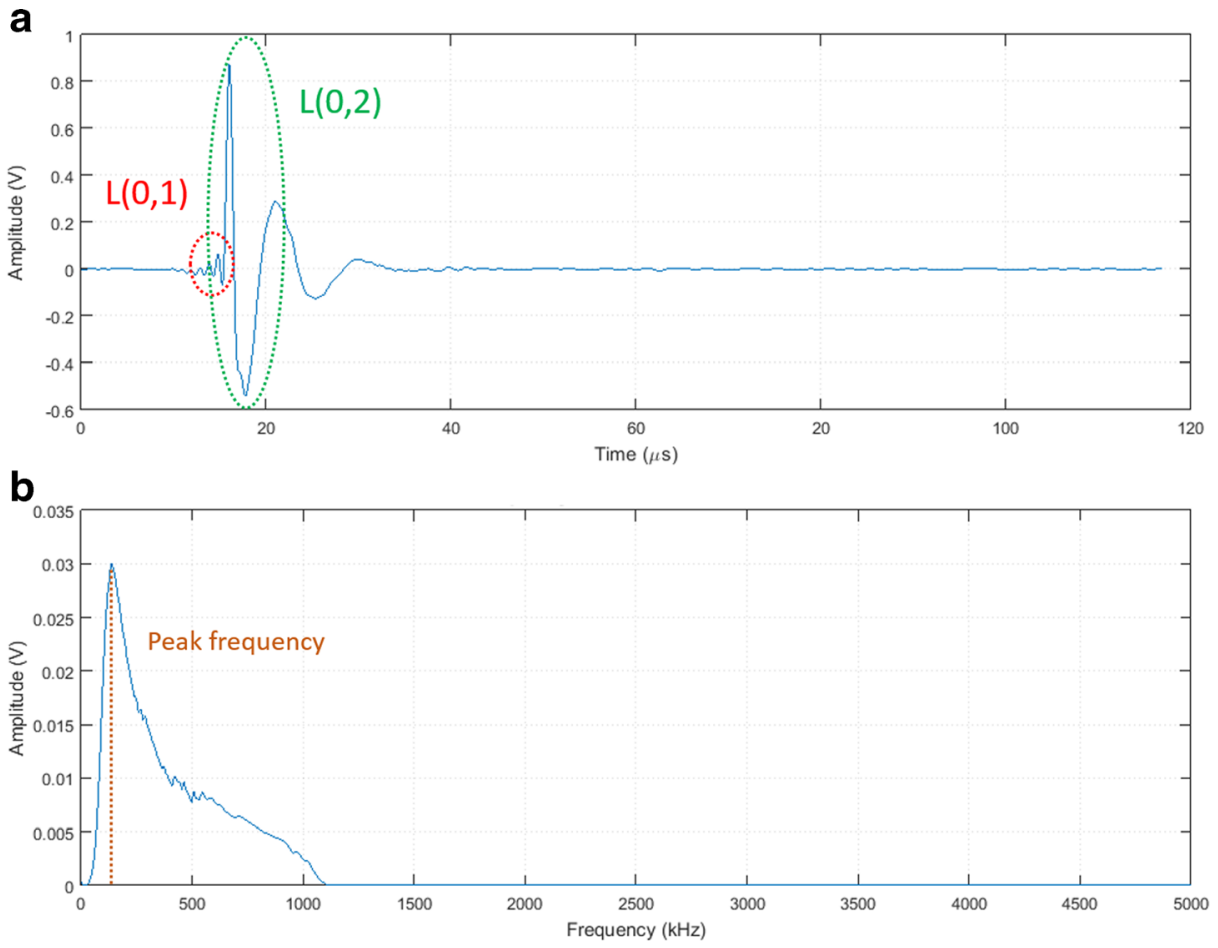

Fig. 13 AE signal received by Sensor 1: (a) signal waveform, and (b) FFT of the signal 


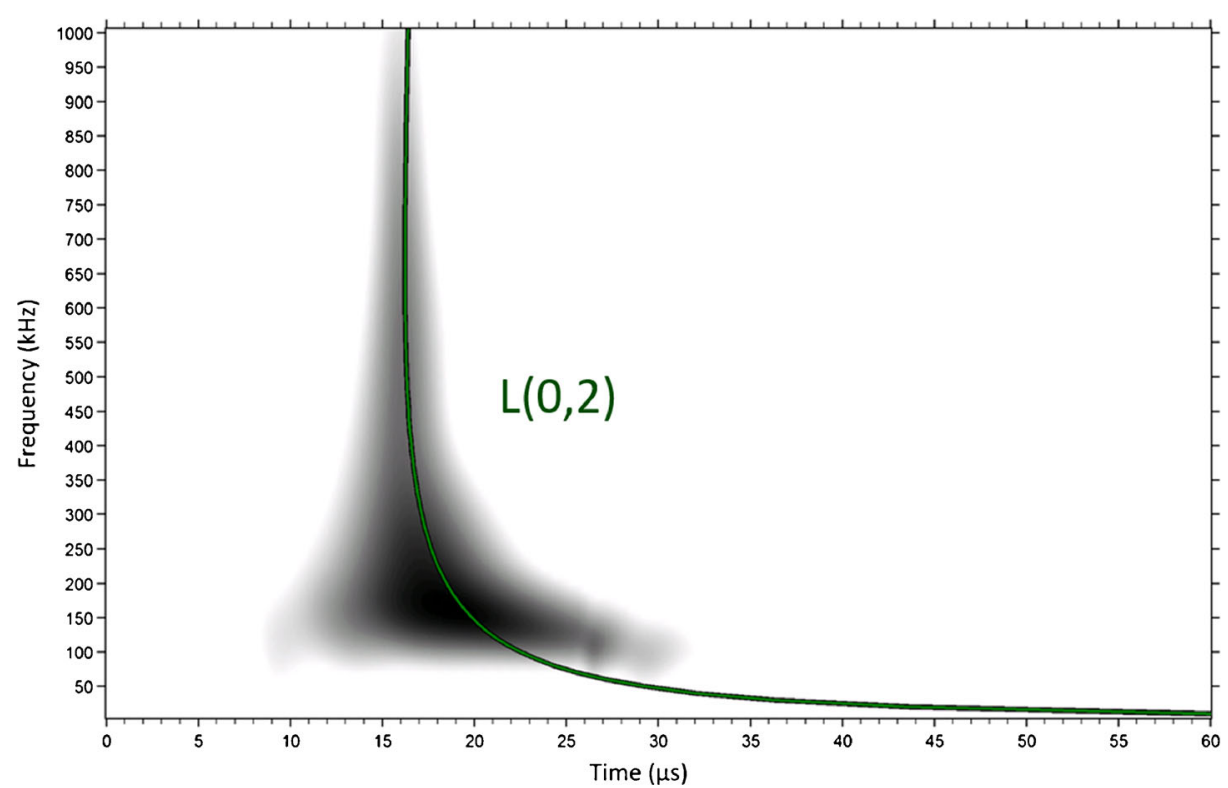

Fig. 14 CWT of AE signal received by Sensor 1 on the sample after impact with superimposed 2nd order longitudinal mode after converting group velocity to time based on the propagation distance of the wave
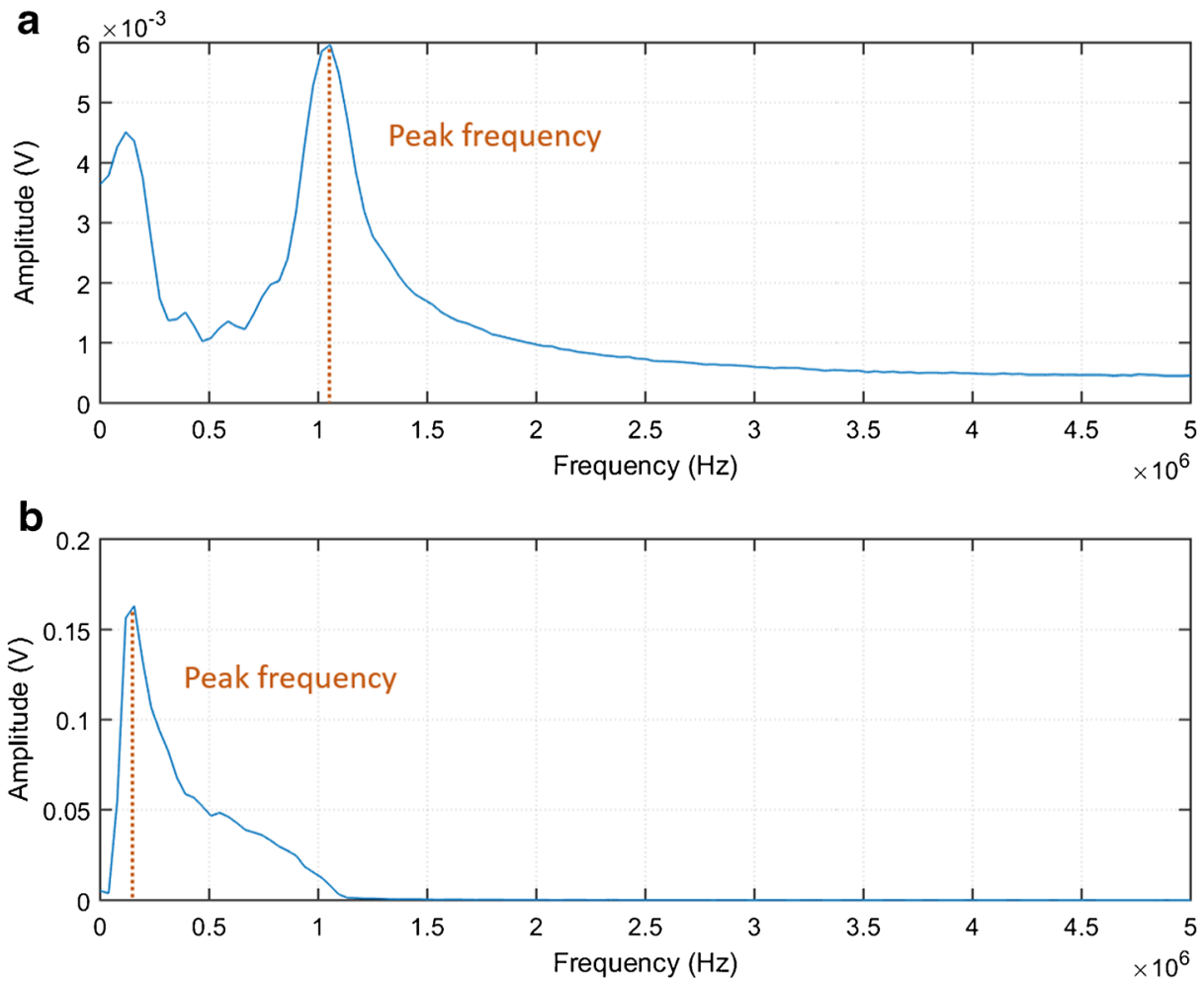

Fig. 15 FFT of (a) L $(0,1)$ mode, and (b) L $(0,2)$ mode of the AE signal received at Sensor 1 
Table 7 Amplitude and frequency distributions of AE signals

\begin{tabular}{lllll}
\hline Sensor & Maximum amplitude $(\mathrm{dB})$ & \multicolumn{2}{l}{ Peak frequency $(\mathrm{kHz})$} \\
\cline { 3 - 5 } & & Full signal & $\mathrm{L}(0,1)$ & $\mathrm{L}(0,2)$ \\
\hline 1 & 99 & 170 & 1050 & 170 \\
2 & 77 & 170 & 1050 & 170 \\
3 & 89 & 170 & 1050 & 170 \\
4 & 98 & 170 & 1050 & 170 \\
\hline
\end{tabular}

frequency against time. The CWTs were calculated using AGU-Vallen Wavelet - a freeware software program [63]. This figure shows the distribution of the energy of the signal as a function of time (or group velocity), frequency, and mode. The dispersion curve for the $\mathrm{L}(0,2)$ mode is superimposed on the CWT in Fig. 14, and shows clearly the presence of this mode in the signal, in the frequency range $50 \mathrm{kHz}-1 \mathrm{MHz}$.

Separation of each signal into the $\mathrm{L}(0,1)$ and $\mathrm{L}(0,2)$ components allowed the peak frequency of each mode to be revealed. The two FFT for Sensor 1 are shown in Fig. 15. The signals received by all of the sensors were of a similar nature; the maximum amplitude and peak frequency of each signal are stated in Table 7.

The amplitude and frequency distributions both indicate fibre breakage within the specimen, falling in line with values reported in the literature for composites, however it is difficult to determine which of the modes indicates specific types of damage in the material. Since there were four sensors bonded to the specimen, and the wave group velocity is known from the dispersion curves (Fig. 4), it was also possible to estimate the location of the impact using only the received AE signals. This was in agreement with the known impact location (Fig. 16).

\subsection{Microscopy of Fracture Cross-Sections}

Figures 17 and 18 show the cross-sections of the damage resulting from the $10 \mathrm{~J}$ and $5 \mathrm{~J}$ impacts on Samples 1 and 3, respectively. In both cases the tube was cut into smaller lengths to be able to examine the progression of the damage through-the-thickness and along-the-length. Figure 16 is a schematic describing the naming convention used for the micrographs. The difference between the two impacts is clearly demonstrated by the damage in each specimen. In both cases there is a transverse matrix crack close to the surface of the material. In Sample 1, this develops into a delamination between the axial carbon fibre and circumferential glass fibre plies which are clearly distinguishable in the images. There is some glass fibre breakage visible in both samples, through both glass fibre plies in the case of Sample 1.

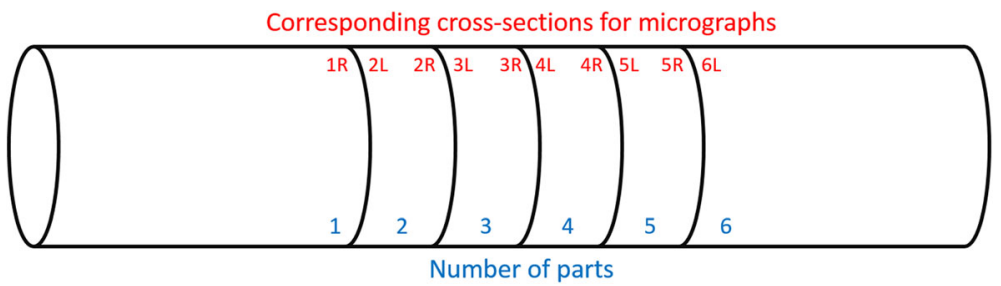

Fig. 16 Schematic of micrograph naming convention where R and L refer to the right and left cross-sections of the cut, respectively. Each sample was cut into 5 or 6 sections for microscopy 

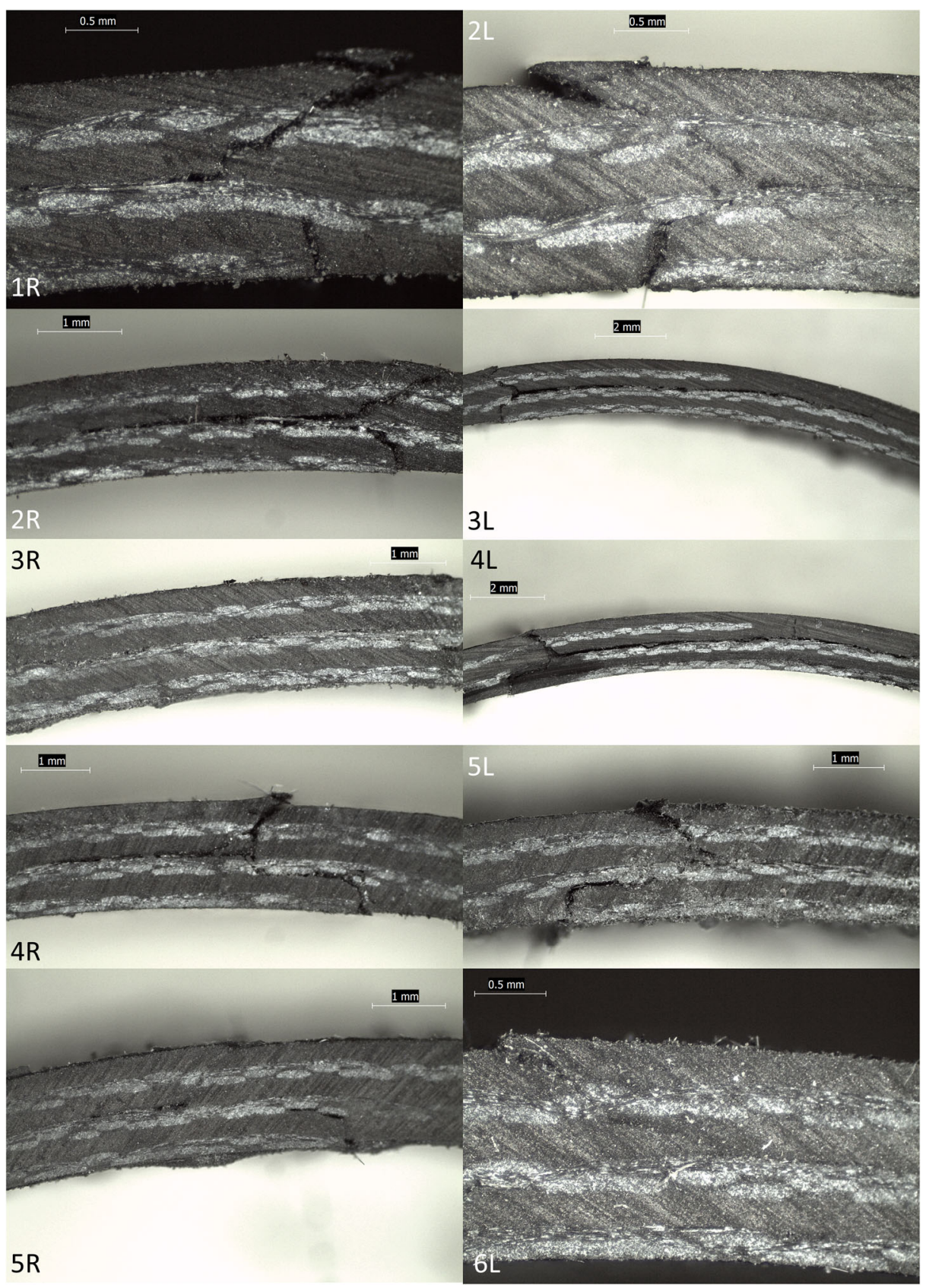

Fig. 17 Micrographs of Sample 1 (10 J impact)

Figure 19 clearly shows the delamination between the second carbon and glass fibre plies due to the $10 \mathrm{~J}$ impact on Sample 1. At the centre of the impact (Fig. 17-3L) the delamination stretches approximately $12 \mathrm{~mm}$ around the circumference of the tube, and is connected to both the inner and outer surfaces by transverse matrix cracks between the 


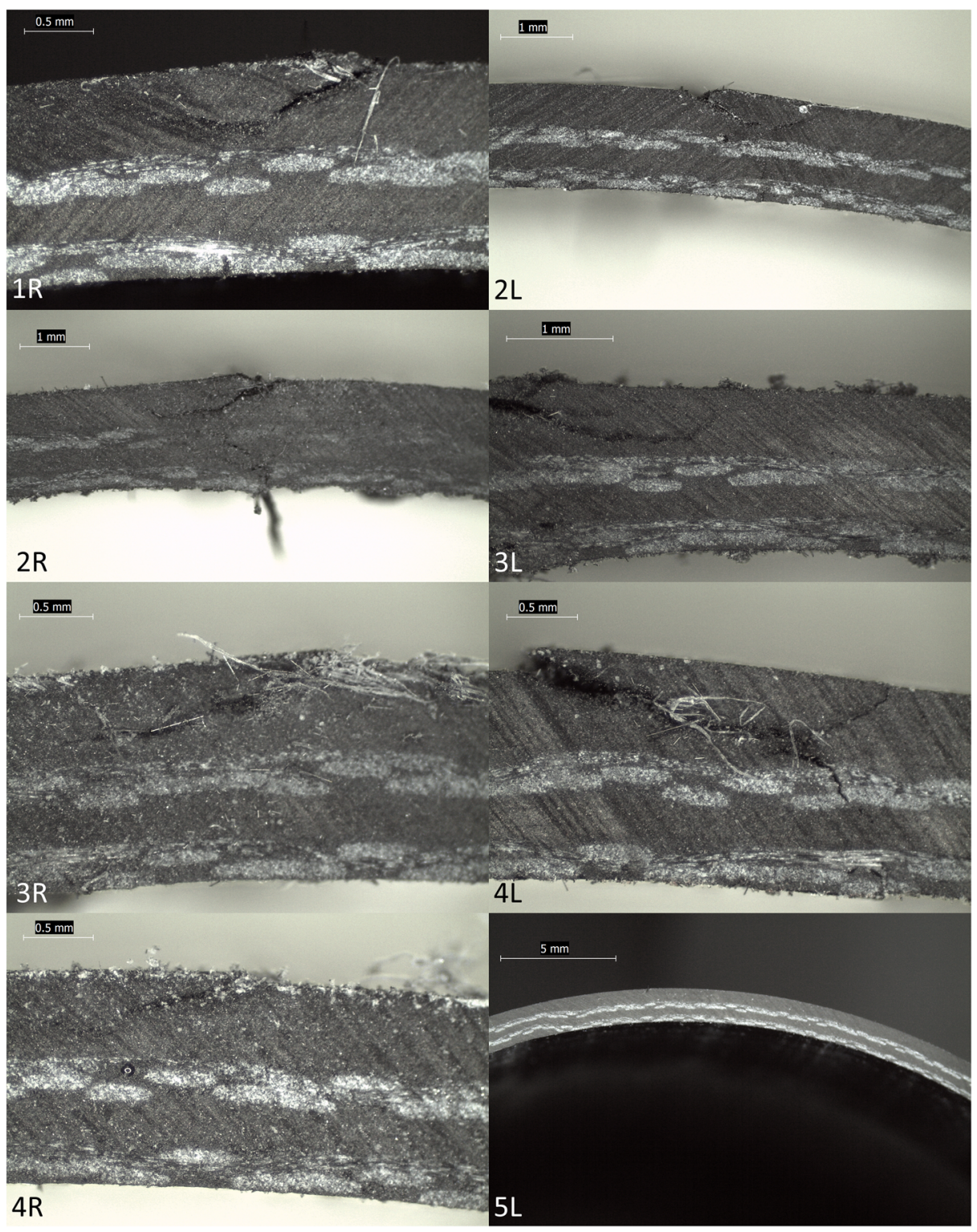

Fig. 18 Micrographs of Sample 3 (5 J impact)

carbon fibres, and breakages in the circumferentially oriented glass fibres. The outer transverse crack has been identified using the thermal mapping, however the inner crack was not visible by this method due to it being in the "shadow" of the crack on the outer surface. A similar phenomenon is observed in the cross-section of Sample 2 (Fig. 20) where the transverse cracks connect in the middle. The delamination is not as obvious in this sample, however it is visible. These micrographs present a strong case for linking the energy of the impact to the extent and type of damage observed. The micrograph of the cross-section of Sample 4 (Fig. 21) confirms again the possibility that the impact did not 


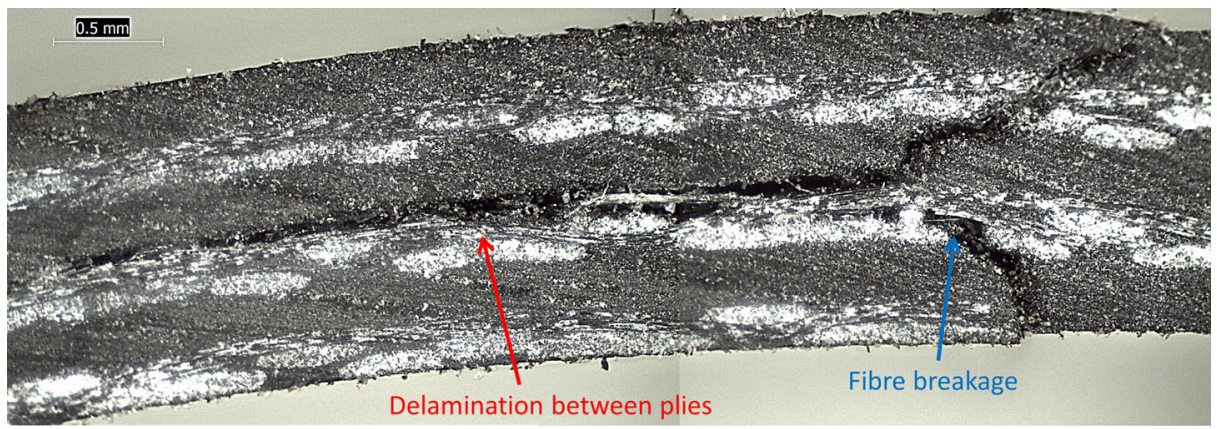

Fig. 19 Cross-section of impact on Sample 1-10 J impact (corresponding to image 2R)

strike the tube at the top of its circumference, thus more severe damage is observed around the circumference of the tube. The separation between plies is clearly visible, as with Sample 1.

Table 8 summarises the damage modes and some quantitative data lifted from the thermal diffusivity and depth mappings, and optical micrographs. The area of damaged was measured by analysis of the thermal diffusivity and depth mappings using the colour threshold function in Image $J[64,65]$. It is clear that there is some discrepancy between the data obtained from each of the techniques used. There are some points worth noting with regards to this, particularly when comparing the area of damage obtained from the thermal diffusivity and depth mapping. The surface of the impact on Sample 4 was coated in a matt black acrylic paint to reduce the reflection of light when imaging. Samples 2-4 follow a trend in that the estimated area of damage is higher when taken from the thermal diffusivity mapping; this may be due to the variation in the fitting used in each process (Eqs. 2 and 3). The estimation of damage area does not follow this trend for Sample 1, where it is possible that the regions of high thermal diffusivity in the diffusivity mapping may have contributed to a lower estimation. A comparison of the damage types identified from the micrographs suggests that, for this specimen, there is a threshold between 7.5-10 J which results in the severe delamination, while below this impact energy, only matrix cracking and glass fibre breakage occur.

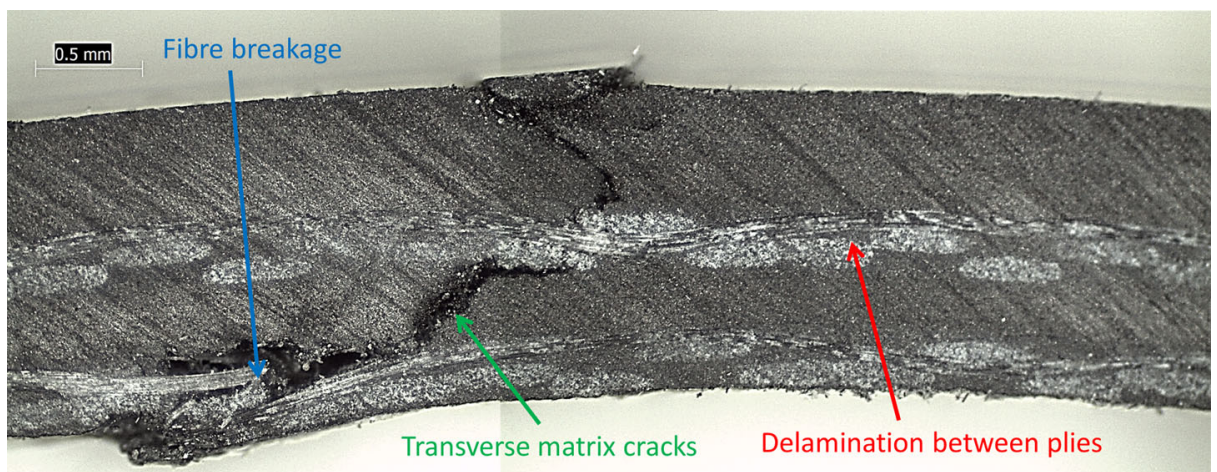

Fig. 20 Cross-section of impact on Sample 2-7.5 J impact 


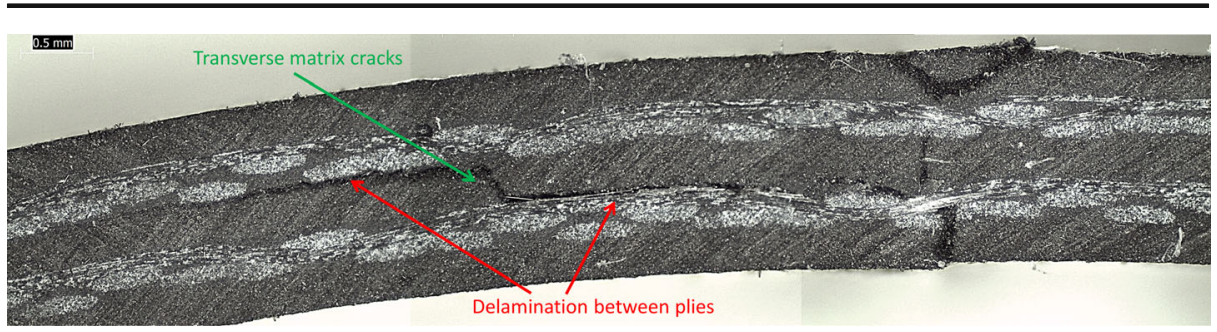

Fig. 21 Cross-section of damage on Sample 4-10 J impact

\section{Concluding Remarks}

The work presented in this paper clearly demonstrates the benefit of the combination of NDT and SHM for improving the confidence and reliability of using composite materials. The use of composites is on the rise. In many industries certification represents a major challenge, especially aerospace and nuclear. The monitoring of structures in-situ and in real time provides an insight into the true challenges of the environment, while information about in-service damage can improve modelling and simulation of specific systems.

Acoustic emission monitoring has been shown to detect and locate damage in composites, though a more thorough investigation regarding analysis of signals is required to be able to distinguish different damage modes. This is especially the case with impact damage, as a single waveform can often comprise multiple wave modes which may result from different mechanisms. Careful thresholding of the recorded signals to eliminate external noise can ensure that damage events are detected and monitored, with their severity and locations recorded. Development of pattern recognition algorithms has also shown promise in the discrimination of physical mechanisms [16].

Active infrared thermography, heat pulse in particular, has already begun to replace traditional ultrasonic inspection of aerospace components [27] since it is an inherently fast, safe, non-contact, versatile technique. The results presented here show clearly the ability to detect impact damage in composite materials, and to be able to predict approximately the extent of damage. IRT represents a useful tool in both the manufacturing and in-service phases of a component, to detect manufacturing defects and in-service damage events, respectively. Surface coatings that reduce the reflection from the surface may be particularly useful for improving the thermal contrast of

Table 8 Comparison of defect size and geometry from diffusivity mapping, thermal depth mapping, and microscopy

\begin{tabular}{|c|c|c|c|c|c|}
\hline \multirow[t]{2}{*}{ Sample } & \multirow[t]{2}{*}{ Damage type } & \multicolumn{2}{|c|}{ Area of damage $\left(\mathrm{mm}^{2}\right)$} & \multicolumn{2}{|c|}{ Depth of damage (mm) } \\
\hline & & $\begin{array}{l}\text { Diffusivity } \\
\text { mapping }\end{array}$ & $\begin{array}{l}\text { Thermal depth } \\
\text { mapping }\end{array}$ & $\begin{array}{l}\text { Thermal depth } \\
\text { mapping }\end{array}$ & Microscopy \\
\hline 1 & $\begin{array}{l}\text { Matrix cracking, fibre } \\
\text { breakage, delamination }\end{array}$ & 502.7 & 604 & $0.4-0.5$ & $0.7-0.8$ \\
\hline 2 & $\begin{array}{l}\text { Matrix cracking, fibre } \\
\text { breakage, delamination }\end{array}$ & 167.2 & 148.7 & $0.5-0.6$ & $0.7-0.8$ \\
\hline 3 & Matrix cracking, fibre breakage & 190.2 & 136.4 & $0.5-0.6$ & 0.4 \\
\hline 4 & $\begin{array}{l}\text { Matrix cracking, fibre } \\
\text { breakage, delamination }\end{array}$ & 120.5 & 58.9 & $0.5-0.6$ & $0.9-1$ \\
\hline
\end{tabular}


defects, though this could present a challenge for assessment of large structures. For in-situ inspection it may be necessary to resolve some of the assumptions mentioned in section 2, such as the exact thickness and architecture of the specimen for optimisation of the mappings obtained.

A critical limitation of IRT is the interrogation depth through the thickness of a specimen. As shown in this work, it is possible for shallow subsurface cracks to mask the damage that lies beneath. Continuous monitoring by a technique such as AE may divulge more accurate data which can prompt more thorough inspections. Validation through optical microscopy can be a useful tool in optimising further the thermal imaging process to ensure the accurate prediction of the depth of damage.

Acknowledgments The authors would like to acknowledge the funding and technical support from BP through the BP International Centre for Advanced Materials (BP-ICAM) which made this research possible. The authors also acknowledge financial support from EPSRC (EP/L01680X) through the Materials for Demanding Environments Centre for Doctoral Training and use of facilities at the Aerospace Research Institute and the Northwest Composites Centre at the University of Manchester. Moreover, I would like to acknowledge Xiaoming Li for providing the raw data of the acoustic emission used in this paper.

Open Access This article is distributed under the terms of the Creative Commons Attribution 4.0 International License (http://creativecommons.org/licenses/by/4.0/), which permits unrestricted use, distribution, and reproduction in any medium, provided you give appropriate credit to the original author(s) and the source, provide a link to the Creative Commons license, and indicate if changes were made.

\section{References}

1. Rose J.L.: Ultrasonic guided waves in structural health monitoring. Key Eng. Mater. 270-273, 14-21 (2004). doi:10.4028/www.scientific.net/KEM.270-273.14

2. Cheng L., Tian G.Y.: Surface crack detection for carbon fiber reinforced plastic (CFRP) materials using pulsed eddy current thermography. IEEE Sensors J. 11, 3261-3268 (2011). doi:10.1109/JSEN.2011.2157492

3. Cawley P.: The rapid non-destructive inspection of large composite structures. Composites. 25, 351-357 (1994). doi:10.1016/S0010-4361(94)80005-7

4. Hung Y.Y.: Shearography for the nondestructive evaluation of composite structures. Opt. Lasers Eng. 24, 161-182 (1996). doi:10.1016/0143-8166(95)00020-8

5. Hung Y.Y., Chen Y.S., Ng S.P., Liu L., Huang Y.H., Luk B.L., Ip R.W.L., Wu C.M.L., Chung P.S.: Review and comparison of shearography and active thermography for nondestructive evaluation. Mater. Sci. Eng. R Reports. 64, 73-112 (2009). doi:10.1016/j.mser.2008.11.001

6. Meola C., Carlomagno G.M.: Recent advances in the use of infrared thermography. Meas. Sci. Technol. 15, R27-R58 (2004). doi:10.1088/0957-0233/15/9/R01

7. Meola C., Carlomagno G.M., Giorleo L.: Geometrical limitations to detection of defects in composites by means of infrared thermography. J. Nondestruct. Eval. 23, 125-132 (2004). doi:10.1007/s10921-004-0819-z

8. Mayr, G., Hendorfer, G.: Porosity Determination by Pulsed Thermography in Reflection Mode, in: 10th Int. Conf. Quant. InfraRed Thermogr. (QIRT 2010), Quebec, Canada, (2010). doi:10.1016/j.msea.2006.10.069

9. Mayr G., Plank B., Sekelja J., Hendorfer G.: Active thermography as a quantitative method for nondestructive evaluation of porous carbon fiber reinforced polymers. NDT E Int. 44, 537-543 (2011). doi:10.1016/j.ndteint.2011.05.012

10. Kordatos E.Z., Aggelis D.G., Matikas T.E.: Monitoring mechanical damage in structural materials using complimentary NDE techniques based on thermography and acoustic emission. Compos. Part B Eng. 43, 2676-2686 (2012). doi:10.1016/j.compositesb.2011.12.013

11. Maldague X.P.V.: Introduction to NDT by active infrared thermography. Mater. Eval. 60, 1060-1073 (2002)http://w3.gel.ulaval.ca/ maldagx/r_1221t.pdf

12. Usamentiaga R., Venegas P., Guerediaga J., Vega L., Lo I.: Feature extraction and analysis for automatic characterization of impact damage in carbon fiber composites using active thermography. NDT E Int. 54, 123-132 (2013). doi:10.1016/j.ndteint.2012.12.011

13. Ley, O., Godinez, V.: Non-destructive evaluation (NDE) of aerospace composites: application of infrared (IR) thermography, in: V.M. Karbhari (Ed.), Non-Destructive Eval. Polym. Matrix Compos., p. 309-336e. Woodhead Publishing Ltd (2013). doi:10.1533/9780857093554.3.309 
14. Bagavathiappan S., Lahiri B.B., Saravanan T., Philip J., Jayakumar T.: Infrared thermography for condition monitoring - a review. Infrared Phys. Technol. 60, 35-55 (2013). doi:10.1016/j.infrared.2013.03.006

15. Avdelidis, N.P., Gan, T.-H.: Non-destructive evaluation (NDE) of Composites: infrared (IR) thermography of wind turbine blades, in: V.M. Karbhari (Ed.), Non-Destructive Eval. Polym. Matrix Compos., p. 634-650e. Woodhead Publishing Ltd (2013) doi:10.1533/9780857093554.4.634

16. Munoz V., Valès B., Perrin M., Pastor M.L., Welemane H., Cantarel A., Karama M.: Damage detection in CFRP by coupling acoustic emission and infrared thermography. Compos. Part B Eng. 85, 68-75 (2016). doi:10.1016/j.compositesb.2015.09.011

17. Montesano J., Fawaz Z., Bougherara H.: Use of infrared thermography to investigate the fatigue behavior of a carbon fiber reinforced polymer composite. Compos. Struct. 97, 76-83 (2013). doi:10.1016/j. compstruct.2012.09.046

18. Gresil M., Giurgiutiu V.: Guided wave propagation in composite laminates using piezoelectric wafer active sensor. Aeronaut. J. 117, 971-995 (2013). doi:10.1117/12.2009254

19. Sánchez D.M., Gresil M., Soutis C.: Distributed internal strain measurement during composite manufacturing using optical fibre sensors. Compos. Sci. Technol. 120, 49-57 (2015). doi:10.1016/j. compscitech.2015.09.023

20. Gresil M., Saleh M., Soutis C.: Transverse crack detection in 3D angle interlock glass fibre composites using acoustic emission. Materials (Basel). 9, 699-718 (2016)

21. Güemes, A., Fernández-López, A., Fernandez, P., Damage Detection in Composite Structures from Fibre Optic Distributed Strain Measurements, in: 7th Eur. Work. Struct. Heal. Monit., Nantes, 528-535 (2014)

22. Fu, T., Liu, Y., Lau, K.-T., Leng, J.: Impact source identification in a carbon fiber reinforced polymer plate by using embedded fiber optic acoustic emission sensors, (2014). doi:10.1016/j. compositesb.2014.06.004.

23. Zhao X., Gao H., Zhang G., Ayhan B., Yan F., Kwan C., Rose J.L.: Active health monitoring of an aircraft wing with an embedded piezoelectric sensor/actuator network: II. Wireless approaches, Smart Mater. Struct. 16, 1208-1217 (2007). doi:10.1088/0964-1726/16/4/033

24. Di Sante R.: Fibre optic sensors for structural health monitoring of aircraft composite structures: recent advances and applications. Sensors. 15, 18666-18713 (2015). doi:10.3390/s150818666

25. Ibarra-Castanedo, C., Genest, M., Guibert, S., Piau, J.-M., Maldague, X.P.V, Bendada, A., Inspection of aerospace materials by pulsed thermography, lock-in thermography, and vibrothermography: a comparative study, in: K.M. Knettel, V.P. Vavilov, J.J. Miles (Eds.), Proc. SPIE 6541, Thermosense XXIX, p. 10. (2007) doi: $10.1117 / 12.720097$

26. Shepard, S.M.: Flash Thermography of Aerospace Composites, IV Conf. Panam. END Buenos Aires. 7 (2007). http://www.ndt.net/article/panndt2007/papers/132.pdf

27. Vijayaraghavan G.K., Sundaravalli S.: Evaluation of pits in GRP composite pipes by thermal NDT technique. J. Reinf. Plast. Compos. 30, 1599-1604 (2011). doi:10.1177/0731684411423119

28. Parker W.J., Jenkins R.J., Butler C.P., Abbott G.L.: Flash method of determining thermal diffusivity, heat capacity, and thermal conductivity. J. Appl. Phys. 32, 1679-1684 (1961). doi:10.1063/1.1728417

29. Roche, J., Balageas, D.: Detection and characterization of composite real-life damage by the TSRpolynomial coefficients RGB-projection technique, in: 12th Int. Conf. Quant. InfraRed Thermogr. (QIRT 2014), Bordeaux, France pp. 1-10. (2014) doi:10.13140/2.1.5004.7362

30. Roche J.M., Leroy F.H., Balageas D.L.: Images of thermographic signal reconstruction coefficients: a simple way for rapid and efficient detection of discontinuities. Mater. Eval. 72, 73-82 (2014). doi:10.21611/qirt.2014.002

31. Silk M.G., Bainton K.F.: The propagation in metal tubing of ultrasonic wave modes equivalent to lamb waves. Ultrasonics. 17, 11-19 (1979). doi:10.1016/0041-624X(79)90006-4

32. Rose, J.L.: Successes and Challenges in Ultrasonic Guided Waves for NDT and SHM, in: Proc. Natl. Semin. Exhib. Non-Destructive Eval., (2009)

33. Su,Z., Ye, L.: Identification of damage using Lamb waves, Springer, (2009) doi:10.1007/978-90-481-9809-2

34. Giurgiutiu, V., Structural Health Monitoring with Piezoelectric Wafer Active Sensors, First, Elsevier, (2008) doi:10.1017/CBO9781107415324.004

35. Hamstad M.A.: Testing fiber composites with acoustic emission monitoring. J. Acoust. Emiss. 1, 151-164 (1982)

36. Mehan R.L., Mullin J.V.: Analysis of composite failure mechanisms using acoustic emissions. J. Compos. Mater. 5, 266-269 (1971)

37. Godin N., Huguet S., Gaertner R.: Integration of the Kohonen's self-organising map and k-means algorithm for the segmentation of the AE data collected during tensile tests on cross-ply composites. NDT E Int. 38, 299-309 (2005). doi:10.1016/j.ndteint.2004.09.006

38. Masmoudi S., El Mahi A., Turki S., El Guerjouma R.: Mechanical behavior and health monitoring by acoustic emission of unidirectional and cross-ply laminates integrated by piezoelectric implant. Appl. Acoust. 86, 118-125 (2014). doi:10.1016/j.apacoust.2014.04.011 
39. Masmoudi S., El Mahi A., El Guerjouma R.: Mechanical behaviour and health monitoring by acoustic emission of sandwich composite integrated by piezoelectric implant. Compos. Part B Eng. 67, 76-83 (2014). doi:10.1016/j.compositesb.2014.05.032

40. Kim S.-T., Lee Y.-T.: Characteristics of damage and fracture process of carbon fiber reinforced plastic under loading-unloading test by using AE method. Mater. Sci. Eng. A. 234-236, 322-326 (1997). doi:10.1016 /S0921-5093(97)00226-8

41. Wadim J.R.: Acoustic Emission Applications. Dunegan Endevco, San Juan Capistrano (1978)

42. Chen O., Karandikar P., Takeda N., Kishi T.: Acoustic emission characterization of a glass-matrix composite. Nondestruct. Test. Eval. 8-9, 869-878 (1992). doi:10.1080/10589759208952759

43. Ceysson O., Salvia M., Vincent L.: Damage mechanisms characterisation of carbon fibre/epoxy composite laminates by both electrical resistance measurements and acoustic emission analysis. Scr. Mater. 34, 12731280 (1996). doi:10.1016/1359-6462(95)00638-9

44. Kotsikos G., Evans J.T., Gibson A.G., Hale J.: Use of acoustic emission to characterize corrosion fatigue damage accumulation in glass fiber reinforced polyester laminates. Polym. Compos. 20, 689-696 (1999). doi: $10.1002 /$ pc. 10392

45. Gong X.L., Gong X.J., Laksimi A., Benzeggagh M.L.: Application of Tsai-Wu criterion to notched and Unnotched composite laminates under torque loading. J. Compos. Mater. 34, 460-478 (2000)

46. Barré S., Benzeggagh M.L.: On the use of acoustic emission to investigate damage mechanisms in glassfibre-reinforced polypropylene. Compos. Sci. Technol. 52, 369-376 (1994). doi:10.1016/0266-3538(94 )90171-6

47. Komai K., Minoshima K., Shibutani T.: Investigations of the fracture mechanism of carbon/epoxy composites by AE signal analyses. JSME Int. J. 34, 381-388 (1991). doi:10.1299/kikaia.56.1792

48. Li L., Lomov S.V., Yan X., Carvelli V.: Cluster analysis of acoustic emission signals for 2D and 3D woven glass/epoxy composites. Compos. Struct. 116, 286-299 (2014). doi:10.1016/j.compstruct.2014.05.023

49. Liu P.F., Chu J.K., Liu Y.L., Zheng J.Y.: A study on the failure mechanisms of carbon fiber/epoxy composite laminates using acoustic emission. Mater. Des. 37, 228-235 (2012). doi:10.1016/j.matdes.2011.12.015

50. Russell, S. S., Henneke, E.G.: Signature analysis of acoustic emission from graphite/epoxy composites., Interim Report, NASA Grant NSG 1238. Report No. (1997)

51. de Groot P.J., Wijnen P.A.M., Janssen R.B.F.: Real-time frequency determination of acoustic emission for different fracture mechanisms in carbon/epoxy composites. Compos. Sci. Technol. 55, 405-412 (1995). doi:10.1016/0266-3538(95)00121-2

52. Suzuki M., Nakanishi H., Iwamoto M., Jiao G.-K., Koike K., Imura M.: Fatigue fracture mechanism of class A-SMC by acoustic emission method. J. Soc. Mater. Sci. Japan. 36, 1402-1408 (1987)

53. Suzuki M., Kida S., Shimbo M., Miyano Y.: Effects of fiber content on fracture mechanisms of short fiber reinforced PET composites. Trans. Japanese Soc. Mech. Eng. Ser. A. 56, 1030-1035 (1990)

54. Ramirez-Jimenez C.R., Papadakis N., Reynolds N., Gan T.H., Purnell P., Pharaoh M.: Identification of failure modes in glass/polypropylene composites by means of the primary frequency content of the acoustic emission event. Compos. Sci. Technol. 64, 1819-1827 (2004). doi:10.1016/j.compscitech.2004.01.008

55. Gutkin R., Green C.J., Vangrattanachai S., Pinho S.T., Robinson P., Curtis P.T.: On acoustic emission for failure investigation in CFRP: pattern recognition and peak frequency analyses. Mech. Syst. Signal Process. 25, 1393-1407 (2011). doi:10.1016/j.ymssp.2010.11.014

56. Bussiba A., Kupiec M., Ifergane S., Piat R., Böhlke T.: Damage evolution and fracture events sequence in various composites by acoustic emission technique. Compos. Sci. Technol. 68, 1144-1155 (2008). doi:10.1016/j.compscitech.2007.08.032

57. Jong H.-J.: Transverse cracking in a cross-ply composite laminate - detection in acoustic emission and source characterization. J. Compos. Mater. 40, 37-69 (2006). doi:10.1177/0021998305053507

58. Mahdavi H.R., Rahimi G.H., Farrokhabadi A.: Failure analysis of $\left( \pm 55^{\circ}\right) 9$ filament-wound GRE pipes using acoustic emission technique. Eng. Fail. Anal. 62, 178-187 (2015). doi:10.1016/j. engfailanal.2015.12.004

59. Ben Khalifa A., Zidi M., Abdelwahed L.: Mechanical characterization of glass/vinylester $+/-55^{\prime}$ filament wound pipes by acoustic emission under axial monotonic loading. Comptes Rendus - Mec. 340, 453-460 (2012). doi:10.1016/j.crme.2012.02.006

60. Dong L., Mistry J.: Acoustic emission monitoring of composite cylinders. Compos. Struct. 40, 149-158 (1998). doi:10.1088/1742-6596/305/1/012044

61. Chou H.Y., Mouritz A.P., Bannister M.K., Bunsell A.R.: Acoustic emission analysis of composite pressure vessels under constant and cyclic pressure. Compos. Part A Appl. Sci. Manuf. 70, 111-120 (2015). doi:10.1016/j.compositesa.2014.11.027

62. ASTM International.: ASTM G14-04 Standard Test Method for Impact Resistance of Pipeline Coatings (Falling Weight Test), (2010) doi:10.1520/G0014-04R10E01.2

63. Vallen-System GmbH.: http://www.vallen.de/wavelet/index.html (2001). (accessed 20 Aug 2016) 
64. Schindelin J., Arganda-Carreras I., Frise E., Kaynig V., Longair M., Pietzsch T., Preibisch S., Rueden C., Saalfeld S., Schmid B., Tinevez J.-Y., White D.J., Hartenstein V., Eliceiri K., Tomancak P., Cardona A.: Fiji: an open-source platform for biological-image analysis. Nat. Methods. 9, 676-682 (2012). doi:10.1038 /nmeth.2019

65. Schindelin. J., Rueden, C.T., Hiner, M.C., Eliceiri, K.W.: The ImageJ ecosystem: An open platform for biomedical image analysis, Mol. Reprod. Dev. (2015, in press) doi:10.1002/mrd.22489 